Long-Term Growth and Short-Term Volatility: The Labour Market Nexus

\author{
Barbara Annicchiarico, Luisa Corrado \\ and Alessandra Pelloni
}

June 2008

CWPE 0823 


\title{
Long-Term Growth and Short-Term Volatility: The Labour Market Nexus*
}

\author{
Barbara Annicchiarico $^{\dagger} \quad$ Luisa Corrado ${ }^{\ddagger} \quad$ Alessandra Pelloni $^{\S}$ \\ July 2008
}

\begin{abstract}
We study the relationship between growth and variability in a DSGE model with nominal rigidities and growth driven by learning-by-doing. We show that this relationship may be positive or negative depending on the impulse source of fluctuations A key role is also played by the Frisch elasticity of labour supply and by institutional features of the labour market. Our general findings are that monetary shocks volatility will generally have a negative effect on growth, while the opposite tends to be true for fiscal and productivity shocks. These findings are somehow consistent with the existing empirical evidence: data show, in fact, a somewhat ambiguous relationship between output growth and real variability, but a generally negative relationship between output growth and nominal variability.
\end{abstract}

J.E.L. Classification: O42, E30, C63.

Keywords: Growth; Volatility; Monetary and Real Shocks; Labour Supply Elasticity; Second-Order Approximation Methods.

*For valuable comments, we are grateful to Gianluca Femminis, Alessandro Piergallini and seminar participants at the University of Padua, the University of Rome "Tor Vergata", the University of Rome "la Sapienza", the University of Bergamo, the University of Naples "Parthenope" and the University of Verona. The usual disclaimer applies. Earlier version circulated as Cambridge Working Paper in Economics, no. 0823.

${ }^{\dagger}$ Department of Economics, University of Rome 'Tor Vergata'. E-mail: Barbara.Annicchiarico@uniroma2.it.

${ }^{\ddagger}$ University of Cambridge, UK and University of Rome 'Tor Vergata'. E-mail: 1c242@econ.cam.ac.uk.

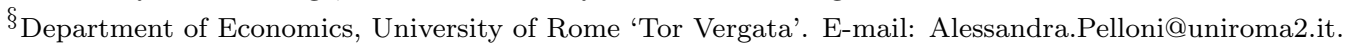




\section{Introduction}

In macroeconomics growth and business cycles have been considered as two separate areas of research. In this paper we attempt to bridge these two areas by proposing a model of endogenous growth that gives a central position to uncertainty.

Until the 1980's macroeconomists regarded short-term economic fluctuations (or business cycles) as deviations around a smooth and stable trend growth path of GDP. Nelson and Plosser (1982) started a debate on the by now accepted fact that output does not show a strong tendency to return to trend after a shock: this fact questions the separation between growth and business cycles analysis. Indeed, the evidence on the persistence of the output process was interpreted by real business cycle theorists as a sign of the nature of the disturbances that caused business cycles, i.e. technological shocks. An alternative explanation to the high persistence of fluctuations comes from models where growth is endogenous: in fact a generally neglected key implication of these models, which are often deterministic, is that any temporary disturbance that has an effect on the amount of growth-enhancing activities can produce permanent effects on the level of output.

Further evidence of a link between growth and cycles is provided by a number of empirical studies which report statistically significant correlations between output growth and output volatility using various cross-section and time series data. Following the seminal paper by Ramey and Ramey (1995), cross-country studies have consistently found that volatility exerts a significant negative impact on long-run (trend) growth, which is however stronger in poorer countries (see Martin and Rogers 2000, Kose et al. 2005, Hnatkovska and Loayza 2005). As to time series methods, using a univariate GARCH model on US data, Caporale and McKiernan (1998) find a positive effect, while Grier and Perry (2000) find no effect in a symmetric bivariate GARCH model of inflation and output growth, and Dawson and Stephenson (1997) reach the same conclusion from an examination of state level data. 
Inflation and/or money average growth and volatility are generally found to negatively affect output growth using cross-section (e.g. Barro 1997 and 2001, Turnovsky and Chattopadhyay 2003), panel data (e.g. Andrés and Hernando 1997, Judson and Orphanides 1999), and time series methods (see Grier and Perry 2000 and Elder 2004). A careful examination of the problems of the different approaches is offered in the overview by Temple (2000). Finally, using multivariate GARCH models, Grier et al. (2004), Fountas et al. (2006) and Andreou et al. (2008) find a generally negative effect of the volatility of money shocks on output growth in G7 countries and a positive effect of growth volatility on output growth.

The existence of a relationship between growth and volatility has important policy implications as it suggests the possibility that policies designed to stabilize short-run fluctuations might also affect the long-run performance of the economy. Depending on whether this relationship is negative or positive, there is the presumption that successful stabilization would also entail either an improvement or deterioration in growth prospects. The potential significance of this is obvious, especially considering that it takes only small changes in the growth rate to produce substantial cumulative gains or losses in output.

It is therefore unsurprising that the relationship between growth and cycles is also receiving an increasing attention in the theoretical literature. ${ }^{1}$ In the so called 'schumpeterian' approach recessions have a positive impact on growth by reducing the opportunity cost of technological improvements. Aghion and Banerjee (2005) note that in this type of models the relationship between volatility and growth is likely to be positive. The relationship will become negative if credit constraints are pervasive, so that R\&D has to be financed by current profits, a condition more relevant for developing countries. However this view is challenged by the empirical evidence on the procyclicality of R\&D expenses (see Walde and Woitek 2004 and Barlevy 2007) in developed countries. In 'arrovian' models where growth takes the form of learning-by-doing, re-

\footnotetext{
${ }^{1}$ A comprehensive overviews are in Gaggl and Steindl (2007) and in Aizenman and Pinto (2005) .
} 
vived by Romer (1986), recessions have a negative effect on growth (e.g. Blackburn 1999, Pelloni 1997 and Stadler 1990). Martin and Rogers (1997) and (2000), Blackburn and Galindev (2003), show that when knowledge (embodied or disembodied) accumulation externality works only through labour, volatility will be detrimental to growth. However, De Hek (1999), going back to Romer's (1986) specification of learning by doing shows that volatility will have a positive effect on growth if the elasticity of the marginal utility of consumption is higher than one. Canton (2002) finds a positive relationship in a model where growth is driven by human capital accumulation and Jones et al. (2005) show that in a large class of convex models of endogenous growth, the relationship between growth and volatility is positive, even when preferences have less curvature than in the logarithmic case, with the magnitude of the effect being U-shaped with respect to the intertemporal elasticity of substitution.

These insights have been established within the context of purely real models of the economy with real shocks and real propagation mechanisms. Stochastic monetary models of endogenous growth are instead studied by Grinols and Turnovsky (1993) and Evans and Kenc (2003) who both derive a negative effect of money uncertainty, and Dotsey and Sarte (2000) and Varvarigos (2008), who find positive effects. Finally in Turnovsky (2000) there's money superneutrality as regards both the rate and the variance of money growth.

While all these papers assume price flexibility, Blackburn and Pelloni (2004) and (2005) propose a model with technology à la Romer (1986) where money enters the utility function and there is nominal wage-setting by unions. They derive a negative relationship between growth and the volatility of nominal shocks and a positive relationship between growth and the volatility of shocks to the rate of subjective time discount.

In this paper we confirm their insight that the sign of the link between growth and volatility may depend on the nature of the shocks. However, we use less restrictive 
assumptions and find many new results.

First, we show that an important parameter in determining the effects of increased uncertainty is the Frisch (compensated) elasticity of labour supply (FELS). ${ }^{2}$ We consider both the case of a competitive labour market and of nominal wage setting, and include fiscal and technology shocks as well as monetary shocks. In all cases we consider how the persistence of the shocks is affecting the results.

In line with the existing literature, we assume a trend growth rate for money subject to stochastic shocks, while the ratio between public expenditure and consumption is constant and also subject to stochastic shocks. Of course many alternative assumptions could be introduced as regards the conduct of fiscal and monetary policies: ${ }^{3}$ we have chosen these hypotheses because they are best suited to understand some mechanisms connecting growth and volatility and to elucidate whether there could be a conflict between long run and short run objectives, thus providing a conceptual basis for the formulation of optimal policies. Under our simple assumptions we find that with nominal rigidity monetary shocks volatility will generally have a negative effect on growth, which however becomes positive when the FELS is high. Uncertainty due to technology shocks leads to higher long-run growth than in a deterministic environment, however the effect is lower the lower is the FELS. Moreover for given variance of the shocks, a higher autocorrelation coefficient in the process governing the shocks will, above a certain threshold, induce a lower average and a higher variance of growth: this means that even if uncertainty increases growth, a negative relationship between growth and its volatility is likely to be observed generating results that are in general

\footnotetext{
${ }^{2} \mathrm{~A}$ parameter that measures the elasticity of total effort with respect to its return is found to influence the relationship between growth and volatility when the utility of leisure is a linear function of human capital by Blackburn and Varvarigos (2008).

${ }^{3}$ The setting of a fixed rate of increase for money was a popular approach to monetary policy in the 1970 s and 1980s. In the past two decades central banks have shifted towards Inflation targeting using the interest rate as an instrument. However, as stressed by Goodfriend (2002) there are several developments that may suggest a shift back from the interest rate to money aggregates as a policy instrument. First, progress in the payment system could make more difficult for a Central Bank to use just the short-term interest rate in the monetary transmission mechanism. Second, standard interest rate rules play no role when nominal interest rates hit the zero bound, as in the case of a Liquidity Trap.
} 
consistent with empirical evidence. This holds under both labour market organizations.

The effect of fiscal shocks volatility on growth is positive with a high elasticity of labour supply, but becomes negative when the elasticity is lower (but still consistent with empirical evidence), or when, for a given level in the variance of the shocks, the serial correlation in the shocks is high enough. Moreover, as it is the case with technology shocks, the persistence in the fiscal shocks is a crucial factor for determining the relationship between growth and volatility.

Finally, we show that the institutional features of the labour market are also important. Not only money shocks, and their variance, have real effects only with nominal wage setting, but the effect of technological variability is higher under nominal wage setting, while the volatility of the fiscal has larger effects on growth in a competitive labour market.

Coming to our solution techniques, it is common practice in macroeconomics to solve nonlinear dynamic stochastic systems using linear methods. However, these methods are not suitable to study the effects of the volatility of the exogenous shocks in complex dynamics environments, since by adopting a linear method all the second order effects will be wiped off. Until recently, this has constrained the literature jointly analysing business cycles and growth to the use of models that could be solved analytically. However some methodological contributions have appeared recently that allow researchers to circumvent this limitation. To evaluate the effects of the volatility of shocks on the endogenous variables of our model we use the perturbation method proposed by Schmitt-Grohé and Uribe (2004), which amounts to a second-order Taylor approximation around a deterministic steady state. ${ }^{4}$ To better understand the interplay between model specification, volatility, and growth, after presenting the model we consider an analytically solvable special case, which is helpful in interpreting the

\footnotetext{
${ }^{4}$ Schmitt-Grohé and Uribe (2004) also provide Matlab codes to compute second-order approximations for any rational expectation model, whose equilibrium conditions can be written in a given form they describe. We are able to use these codes as the model we propose has the required form.
} 
results. We also conduct two types of sensitivity analysis: we vary some preference and technological parameters and consider alternative decompositions of the shock volatility between innovation variance and autocorrelation.

The paper is organised as follows: section two describes the basic stochastic growth model incorporating exogenous monetary disturbances in the process governing money growth, technology and fiscal shocks; section three summarizes the general equilibrium conditions of the model, section four describes some preliminary analytical results, section five applies the perturbation method of Schmitt-Grohé and Uribe (2004) to evaluate the effects of volatility on growth. Section six concludes.

\section{The Model}

We consider an artificial economy in which there are constant populations (normalised to one) of identical, immortal households and identical, competitive firms. Time is discrete and indexed by $t=0,1 \ldots \infty$.

\section{$2.1 \quad$ Firms}

The representative firm combines $N_{t}$ units of labour with $K_{t}$ units of capital to produce $Y_{t}$ units of output according to

$$
\begin{gathered}
Y_{t}=b_{t}\left(\bar{K}_{t} N_{t}\right)^{\alpha} K_{t}^{1-\alpha}, \quad \alpha \in(0,1) \\
b_{t}=C_{b}+\rho_{b} b_{t-1}+\varepsilon_{b, t},
\end{gathered}
$$

where $C_{b}$ and $\rho_{b}$ are constants. The shock $\varepsilon_{b, t}$ is assumed to be identically and independently distributed with mean zero, variance equal to $\sigma_{\varepsilon_{b}}^{2}$ and bounded support. The term $\bar{K}_{t}$ represents an index of knowledge which is freely available to all firms and which is acquired through serendipitous learning-by-doing, as in the classic Romer 
(1986) paper. There is a vast empirical literature that documents the pervasive presence of learning-by-doing effects in the economy. Some recent evidence and references to other studies can be found in Thornton and Thompson (2001), Cooper and Johri (2002) and Jovanovic and Rousseau (2002).

Labour and capital are hired from households at the real wage rate $\frac{W_{t}}{P_{t}}$ and real rental rate $R_{t}$, respectively, where $W_{t}$ is the nominal wage and $P_{t}$ is the price of output. Profit maximisation implies that factors are paid at their marginal productivity:

$$
\begin{gathered}
\frac{W_{t}}{P_{t}}=\alpha b_{t} \bar{K}_{t}^{\alpha} N_{t}^{\alpha-1} K_{t}^{1-\alpha}=\alpha b_{t} N_{t}^{\alpha-1} K_{t}, \\
R_{t}=b_{t}(1-\alpha) \bar{K}_{t}^{\alpha} N_{t}^{\alpha} K_{t}^{-\alpha}-\delta=b_{t}(1-\alpha) N_{t}^{\alpha}-\delta,
\end{gathered}
$$

where $\delta$ is the depreciation rate and the second equalities in the expressions above are the result of a symmetry assumption for firms.

\subsection{Households}

The representative household derives lifetime utility, $U$, according to

$$
U=\sum_{t=0}^{\infty} \beta^{t}\left[\log C_{t}+\mu \log \left(\frac{M_{t}}{P_{t}}\right)-\lambda L_{t}^{\eta}\right], \quad \beta \in(0,1), \quad \lambda, \mu>0, \eta>1
$$

where $C_{t}$ denotes consumption, $\frac{M_{t}}{P_{t}}$ denotes real money balances and $L_{t}$ denotes labour.

We choose a logarithmic specification for utility because it is consistent with additive separability in consumption and leisure, which makes it easier to clarify the mechanisms we are studying. It is also suggested by recent estimates. ${ }^{5}$ To generate

\footnotetext{
${ }^{5}$ The literature on estimation of the IES uses a wide variety of models and data sets. Using the US aggregate consumption data, Hall (1988) found that expected interest rates had no effect on consumption growth. Attanasio and Weber (1993) showed evidence of aggregation bias in testing the Euler equation with aggregate data. Beaudry and van Wincoop (1996) also showed that aggregate data were uninformative in the point estimate of the IES and used a panel of state-level data to conclude that the IES estimate was probably close to one. More recently Vissing-Jorgensen and Attanasio (2003) and Mulligan (2004) results are roughly consistent with log utility specifications.
} 
a demand function for money, we adopt the familiar short-cut device of introducing money directly into the utility function, rather than specifying explicitly a separate transactions technology. The quantity $M_{t-1}$ is understood to denote beginning-ofperiod $t$ (i.e., end-of-period $t-1$ ) nominal cash balances which are augmented by a proportional monetary transfer, $a_{t} .{ }^{6}$ We assume that the disturbance is governed by the following process:

$$
a_{t}=C_{a}+\rho_{a} a_{t-1}+\varepsilon_{a, t}
$$

The shock $\varepsilon_{a, t}$ is assumed to be identically and independently distributed with mean zero, variance equal to $\sigma_{\varepsilon_{a}}^{2}$ and bounded support. $C_{a}$ is a constant, the scalar $\rho_{a}$ is assumed to be less than one. Defining $Z_{t}$ as real assets, the budget constraint for the household is given by

$$
C_{t}+\frac{M_{t}}{P_{t}}+Z_{t+1}=\frac{W_{t}}{P_{t}} L_{t}+\frac{M_{t-1} a_{t}}{P_{t}}+\left(1+R_{t}\right) Z_{t}-S_{t}
$$

where $Z_{t}$ represents wealth and $S_{t}$ is lump-sum taxation.

Each household confronts the problem of maximising the expected value of intertemporal utility in (5), subject to the sequence of budget constraints in (7) and initial conditions for $Z_{0}$ and $M_{0}$. The information set conditioning expectations consists of the values of all parameters, the current and past values of all variables and the probability distributions of all shocks. The problem is solved, in part, by choosing plans for consumption, money balances and asset holdings that satisfy the following conditions:

$$
C_{t}^{-1}=\beta E_{t} C_{t+1}^{-1}\left(1+R_{t+1}\right)
$$

\footnotetext{
${ }^{6}$ In some models, it is end-of-period (rather than beginning-of-period) money holdings that serve as the reference point. To the extent that money yields utility by facilitating transactions, it seems more reasonable to adopt the present formulation. The assumption that monetary transfers are proportional (rather than lump-sum) is made largely for analytical convenience, as in other investigations (e.g., Bénassy 1995).
} 
and

$$
\frac{\mu}{M_{t}}=\frac{\gamma}{C_{t} P_{t}}-E_{t} \beta \frac{\gamma a_{t+1}}{C_{t+1} P_{t+1}}
$$

Using the transversality condition $\lim _{\tau \rightarrow \infty} \beta^{\tau} E_{t}\left(\frac{M_{t+\tau-1} a_{t+\tau}}{P_{t+\tau} C_{t+\tau}}\right)=0$, equation (9) can be solved forward to give:

$$
\frac{M_{t} \gamma}{C_{t} P_{t}}=\mu(1-\beta)^{-1}
$$

We consider two alternative scenarios for the labour market. In the first scenario, the labour market is characterised by monopolistic unions. Bewley's (1999) detailed study of firms' wage policies based on interviews with managers finds ample evidence of downward nominal wage rigidities. More recently, the multi-country study of Dickens et al. (2007) uncovers evidence of significant downward nominal and real wage rigidities in most of the countries in their sample. We assume that wage setting takes place prior to the realisations of shocks, on the basis of one-period contracts. In this case, therefore, the economy displays nominal rigidities, as in the early contracting models of Gray (1976) and Fischer (1977), as well as those of a more recent vintage (e.g., Bénassy 1995). The nominal wage is fixed at the level that maximizes households' expected utility, taking into account the constraint given by labour demand. The optimality condition for the nominal wage is found to be:

$$
\eta \lambda E_{t-1} L_{t}^{\eta}=\alpha W_{t} E_{t-1} L_{t}\left(P_{t} C_{t}\right)^{-1}
$$

Hence in equilibrium the marginal expected benefit of working is equal to the expected cost. In the second scenario, the labour market is perfectly competitive. Labour supply turns out to be:

$$
\frac{W_{t}}{P_{t}} C_{t}^{-1}=\eta \lambda L_{t}^{\eta-1}
$$

From (12) we can see that the Frish elasticity (FELS) is equal to $1 /(\eta-1)$. Households' 
equilibrium is now characterised completely by the first-order conditions in (8) and (10), the optimal condition for the nominal wage (11) or for labour supply (12), the budget constraint in (7), the initial conditions for money holdings and financial wealth and the transversality conditions:

$$
\lim _{\tau \rightarrow \infty} \beta^{\tau} E_{t}\left(\frac{M_{t+\tau-1} a_{t+\tau}}{P_{t+\tau} C_{t+\tau}}\right)=\lim _{\tau \rightarrow \infty} \beta^{\tau} E_{t}\left(\frac{Z_{t+\tau+1}}{C_{t+\tau}}\right)=0 .
$$

\section{General Equilibrium}

The solution of the model is computed by combining the equilibrium conditions for households listed above, with the profit maximization condition for firms (3) and (4), the market clearing conditions for capital, $K_{t}=Z_{t}$, for labour, $N_{t}=L_{t}$, for goods, $C_{t}+K_{t+1}+G_{t}=Y_{t}+(1-\delta) K_{t}$, where $G_{t}$ denotes government spending in period $t$, and for the money market. Money supply, $H_{t}$, moves in conformance with:

$$
H_{t}=a_{t} H_{t-1}
$$

The equilibrium condition for the money market is then $M_{t}=H_{t}$.

We assume that the government runs a continuously balanced budget, so that $G_{t}=S_{t}$. Government expenditure is assumed to evolve according to:

$$
\begin{gathered}
G_{t}=u_{t} C_{t}, \\
u_{t}=C_{u}+\rho_{u} u_{t-1}+\varepsilon_{u, t} .
\end{gathered}
$$

The shock $\varepsilon_{u, t}$ is assumed to be identically and independently distributed with mean zero, variance equal to $\sigma_{\varepsilon_{u}}^{2}$ and bounded support, $C_{u}$ is a constant and the scalar $\rho_{u}$ is assumed to be less than one.

The labour market equilibrium condition with nominal wage setting can be rewrit- 
ten as (derivation in the Appendix):

$$
L_{t}=\left(\frac{\alpha^{2} a_{t} b_{t} K_{t} E_{t-1} L_{t} a_{t}^{-1}}{\eta \lambda C_{t} E_{t-1} L_{t}^{\eta}}\right)^{1 /(1-\alpha)}
$$

When the labour market is competitive, its equilibrium condition, obtained just by equating labor demand (3) and labour supply (12) is:

$$
L_{t}=\left(\frac{K_{t} \alpha b_{t}}{C_{t} \eta \lambda}\right)^{1 /(\eta-\alpha)}
$$

\section{Some Analytical Results}

To pin down some of the mechanisms relating growth and uncertainty, in this section we consider a set of very restrictive assumptions under which the model admits a closed form solution. The findings in this section will be useful in interpreting the results we get by simulation in the extended model.

When $\delta=1$ and the fiscal shock $u_{t}$ is i.i.d., the following relationship, derived in the appendix, holds:

$$
\frac{K_{t+1}}{Y_{t}}=\frac{\varkappa(1+u)}{(1-\varkappa)\left(1+u_{t}\right)+\varkappa(1+u)} .
$$

where $\varkappa \equiv(1-\alpha) \beta$, and $u \equiv E_{t} u_{t+i}$ for $i=1,2 . . \infty$. This implies that the rate of investment is a decreasing and convex function of the fiscal shocks and therefore will increase on average when the variance of the shocks increases, by Jensen's inequality. We'll label this the 'precautionary saving effect'. 


\subsection{Money Wage Setting}

Consider the nominal wage setting scenario. Assume that $\eta=1$, and that all shocks are i.i.d and uncorrelated. We can then derive (see the Appendix):

$$
L_{t}=\frac{\alpha^{2} a_{t}\left[(1-\varkappa)\left(1+u_{t}\right)+\varkappa(1+u)\right]}{(1-\varkappa) \lambda a} .
$$

where $a \equiv E a_{t+i}$ for $i=1,2 \ldots \infty$. Labour is an increasing linear function of the fiscal and the money shock. In fact both shocks cause an increase in aggregate demand and therefore in labour demand.

We can now state the following:

Proposition 1 Assume $\delta=100 \%$, all shocks are i.i.d. and uncorrelated with each other and $\eta$ is equal to one. Then the following expression for the growth rate of output in the presence of money wage setting holds:

$$
\frac{Y_{t+1}}{Y_{t}}-1=b_{t+1} \frac{\left(\frac{\alpha^{2} a_{t+1}\left[\left(1+u_{t+1}\right)(1-\varkappa)+\varkappa(1+u)\right]}{(1-\varkappa) \lambda a}\right)^{\alpha} \varkappa(1+u)}{\left(1+u_{t}\right)(1-\varkappa)+\varkappa(1+u)}-1 .
$$

\section{Proof. See Appendix.}

As we have seen, given the assumed specifications of preferences and technology, the TFP shock has no effect on the marginal choice between leisure and consumption or on the time path of consumption. Growth is then a linear function of the technology shock $b_{t+1}$, through a direct effect on the production function. This means that the variance of this shock will not affect average growth. Growth is instead a strictly concave function of the monetary shock, so its variance will have a negative effect on average growth. The term inside the large parenthesis in (21) is just $L_{t+1}$. Even if expected labour is not affected by $\sigma_{a}^{2}$, as from (20) labour is a linear function of the money shock, however, through the diminishing marginal productivity of labour, i.e. since $\alpha<1$, the expected rate of growth will be affected by $\sigma_{a}^{2}$. We could label this 
the 'diminishing returns to labour' effect. The effects of a mean-preserving spread in the distribution of the fiscal shocks are less immediately readable from (21): the rate of growth is in fact a concave function of the current realizations of the shocks - again through the 'diminishing returns to labour' effect - but a convex function of the lagged realizations of the shocks - through the rate of investment, as can be seen from (19). Calculating a second-order approximation of the rate of output growth as in (21) and taking expectations we get:

$$
E \frac{Y_{t+1}}{Y_{t}}-1 \simeq A-1+A_{a} \sigma_{a}^{2}+A_{u} \sigma_{u}^{2}
$$

with $A \equiv b \varkappa\left(\frac{\alpha^{2}(1+u)}{(1-\varkappa) \lambda}\right)^{\alpha}, A_{a} \equiv \frac{A \alpha(\alpha-1) a^{-2}}{2}<0, A_{u} \equiv \frac{A}{2}\left(\frac{1-\varkappa}{1+u}\right)^{2}[2+\alpha(\alpha-1)]>0$.

We conclude that an increase in $\sigma_{u}^{2}$ causes an increase in precautionary savings which more than offsets the 'diminishing returns to labour effect': the net effect on expected growth is positive.

\subsection{Competitive Labour Market}

When the labour market is competitive equilibrium employment is given by (the derivation is in the Appendix):

$$
L_{t}=\left(\frac{\alpha\left[(1-\varkappa)\left(1+u_{t}\right)+\varkappa(1+u)\right]}{(1-\varkappa) \eta \lambda}\right)^{1 / \eta} .
$$

By comparing (20) and (23) we see that employment will be higher than in the presence of unions, i.e. when labour is sold monopolistically. Labour is an increasing and concave function of $u_{t}$. This means that a mean-preserving spread in the distributions of the fiscal shock will induce employment to decrease on average. The effects of volatility on expected labour are referred in the rest of the paper as 'employment effects'. We are now ready for: 
Proposition 2 Assume $\delta=100 \%$ and all shocks are i.i.d. and uncorrelated. Then the following expression for the rate of growth of output holds if the labour market is competitive:

$$
\frac{Y_{t+1}}{Y_{t}}-1=\frac{b_{t+1} \varkappa\left(\frac{\alpha\left[\left(1+u_{t+1}\right)(1-\varkappa)+\varkappa(1+u)\right]}{(1-\varkappa) \eta \lambda}\right)^{\alpha / \eta}(1+u)}{(1-\varkappa)\left(1+u_{t}\right)+\varkappa(1+u)} .
$$

Proof. See Appendix.

As in the previous case, growth is a linear function of the technology shock $b_{t+1}$, so the variance of this shock will not affect unconditional average growth. The fiscal shocks enter (24) in a fashion analogous to that in which they enter (21), so we expect the effects of an increase in $\sigma_{u}^{2}$ to be similar to those we have seen in the economy with unions. In fact we have the following approximation:

$$
E \frac{Y_{t+1}}{Y_{t}}-1 \simeq B-1+B_{u} \sigma_{u}^{2}
$$

with $B \equiv b \varkappa\left(\frac{\alpha(1+u)}{(1-\varkappa) \eta \lambda}\right)^{\alpha / \eta}, B_{u} \equiv \frac{B}{2}\left(\frac{1-\varkappa}{1+u}\right)^{2}\left[2+\frac{\alpha}{\eta}\left(\frac{\alpha}{\eta}-1\right)\right]>0$.

Intuitively, as in the previous case, an increase in $\sigma_{u}^{2}$ causes an increase in precautionary savings which more than offsets the negative 'employment' and 'diminishing returns to labour' effects. We can also notice that expected growth will be higher than when labour is sold monopolistically (by comparing $A$ and $B$ with $\eta=1$ ) and that the positive effect of volatility on growth will be higher as well (by comparing $A_{u}$ and $B_{u}$ with $\left.\eta=1\right)$.

\section{Simulating the Model}

In order to study the effects of volatility of the exogenous shocks on growth in the general case the model is solved following the numerical method based on accurate second-order approximation to the policy functions representing the optimum paths 
for the control and the endogenous state variables devised by Schmitt-Grohé and Uribe $(2004) .^{7}$

\subsection{Inducing Stationarity}

In this economy a number of variables, such as output, consumption etc. will not be stationary along the balanced-growth path. We therefore perform a change of variables, so as to obtain a set of equilibrium conditions that involve only stationary variables. We note that non stationary variables at time $t$ are cointegrated with $K_{t}$, while the same variables at time $t+1$ are cointegrated with $K_{t+1}$. We divide variables by the appropriate cointegrating factor and denote the corresponding stationary variables with lowercase letters.

Using (15), the economy wide resource constraint can be written as:

$$
1+g_{t+1}=\frac{c_{t+1}}{c_{t}}\left[b_{t} L_{t}^{\alpha}-c_{t}\left(1+u_{t}\right)+1-\delta\right]
$$

where $c_{t} \equiv \frac{C_{t}}{K_{t}}$ and $g_{t+1}=\frac{C_{t+1}}{C_{t}}-1$ i.e. $g_{t}$ indicates consumption growth.

Using (4) and (9), the Euler equation becomes:

$$
1=E_{t} \frac{\beta\left[(1-\alpha) b_{t+1} L_{t+1}^{\alpha}+(1-\delta)\right]}{1+g_{t+1}} .
$$

Equation (10) can be written as:

$$
m_{p, t}=\frac{\mu c_{t}}{1-\beta}
$$

\footnotetext{
${ }^{7}$ Kim et al. (2003) propose an alternative algorithm for calculating second order approximations to the solutions to nonlinear stochastic rational expectation models based on the "state free" approach described in Sims (2001). More recently Lombardo and Sutherland (2007) have proposed a methodology for computing second-order accurate solutions of non-linear rational expectation models using a two-step algorithm devised for the solution of linear expectation models. Their algorithm generates identical results to those reported by Schmitt-Grohé and Uribe (2004) in their example on a stochastic growth model.
} 
where $m_{p t} \equiv \frac{M_{t}}{P_{t} K_{t}}$.

Equation (10) also tells us that inflation $\pi_{t+1}=\frac{P_{t+1}}{P_{t}}-1$ evolves according to:

$$
\left(1+\pi_{t}\right)\left(1+g_{t}\right)=a_{t}
$$

Coming to the labour market equilibrium, (17) in terms of stationary variables becomes:

$$
L_{t}=\left(\frac{\alpha^{2} a_{t} b_{t} E_{t-1} L_{t} a_{t}^{-1}}{\eta \lambda c_{t} E_{t-1} L_{t}^{\eta}}\right)^{1 /(1-\alpha)}
$$

and (18) becomes:

$$
L_{t}=\left(\frac{\alpha b_{t}}{\eta \lambda c_{t}}\right)^{1 /(\eta-\alpha)}
$$

A stationary competitive equilibrium is a set of stationary processes $\left\{c_{t}, g_{t}, m_{p t}, \pi_{t}\right.$, $\left.L_{t}\right\}$ satisfying (26), (27), (28), (29), and (30) (in case of monopolistic wage setting) or (31) (if the labour market is competitive), given the exogenous stochastic processes $\left\{a_{t}, b_{t}, u_{t}\right\}$ and the transversality conditions:

$$
\lim _{\tau \rightarrow \infty} \beta^{\tau} E_{t}\left(\frac{m_{t+\tau}}{c_{t+\tau}}\right)=\lim _{\tau \rightarrow \infty} \beta^{\tau} E_{t}\left(\frac{z_{t+\tau+1}}{c_{t+\tau}}\right)\left(b_{t} L_{t+\tau}^{\alpha}-c_{t+\tau}\left(1+u_{t+\tau}\right)+1-\delta\right)=0
$$

\subsection{Deterministic Balanced Growth Path}

We have now to pin down the deterministic balanced growth path equilibrium, which will be the centre of our approximation. To indicate steady-state variables we drop the time subscript, i.e. $x$ is the steady state value of the generic variable $x_{t}$. We have the following steady-state relationships:

$$
\begin{gathered}
1+g=b L^{\alpha}-c(1+u)+1-\delta, \\
m_{p}=\frac{\mu c}{(1-\beta)},
\end{gathered}
$$




$$
\begin{gathered}
1+g=\beta\left[(1-\alpha) b L^{\alpha}+1-\delta\right], \\
(1+\pi)(1+g)=a, \\
L=\left(\frac{b \alpha^{2}}{\eta \lambda c}\right)^{1 /(\eta-\alpha)}
\end{gathered}
$$

If the labour market is competitive instead of (36) we have

$$
L=\left(\frac{b \alpha}{\eta \lambda c}\right)^{1 /(\eta-\alpha)}
$$

Finally, from (2), (6) and (16):

$$
\begin{gathered}
C_{b}=\left(1-\rho_{b}\right) b, \\
C_{a}=\left(1-\rho_{a}\right) a, \\
C_{u}=\left(1-\rho_{u}\right) u .
\end{gathered}
$$

We will study the implications of higher uncertainty on growth considering first the case of monopolistic nominal wage setting, and then the case of a competitive labour market.

\subsection{Calibration}

To implement the simulation method we have to choose values for the parameters appearing in the equations. The time period in the model is assumed to be one year. For some of these parameters, estimates are available in the empirical literature, others are chosen in order to make the steady-state values of the variables consistent with the data of the US economy. For each parameter we choose a benchmark value. To check for the robustness of our results we then consider a range of other possible values for some of the parameters, fixing the other parameters at their benchmark level. 
The baseline calibration of the model is reported in Table 1, where most of benchmark parameter values are set along the lines of the existing literature. Consistently with Schmitt-Grohé and Uribe (2007) the subjective discount factor $\beta$ equals 0.96, the annual rate of depreciation of capital $\delta$ equals 0.1 and the cost share of labour $\alpha$ is set to 0.7 . We set $\eta$ at 1.5 , while $\mu$ and $\lambda$ are implied values.

The persistence of the money supply shock and the annual standard deviation of the innovation have been estimated over the period 1980-2007 using FRED data for seasonally adjusted M2. As in Schmitt-Grohé and Uribe (2007) the autoregressive parameters in the driving forces $b_{t}$ and $u_{t}$ are set equal to 0.85 and 0.87 , respectively, while the standard deviations of the innovations are $\sigma_{\varepsilon_{b}}=0.0212$ and $\sigma_{\varepsilon_{u}}=0.0102$.

As in Galí et al. (2007) we set the share of government purchases in value added to be 20 percent in steady state, which is in line with the observed U.S. postwar average. In the U.S. M2 was on average about 52 percent of annual GDP over the period 1980 to 2007. King and Rebelo (1999) suggest that the average GDP-capital ratio in the

U.S. is about $50 \%$ on annual basis. This gives steady-state values for $m_{p}$ and $s$ equal to 0.26 and 0.1 , respectively. The steady-state inflation rate is assumed to be 4 percent per year. This value is consistent with the average U.S. consumer price index change over the period 1980-2007. The steady-state value for $L$ is 0.2 . Following Jones et al. (2005) the value for the non-stochastic growth rate of consumption is set to $2 \%$.

\subsection{Volatility and Growth under Monopolistic Wage Setting}

We first consider the effects of nominal and real volatility on growth under the assumption that the nominal wage is set by a monopolistic union prior to the realisations of shocks. In this case monetary shocks and their variance have real effects.

Tables 2-4 report the effects of the volatility of the exogenous shocks on mean consumption growth, $E(g)$. We also report the standard deviations of the growth rate of output, $\sigma_{g}$, and of each relevant shock, $\sigma_{a}, \sigma_{b}, \sigma_{u}$ in turn. The first row of each 
table reports the results obtained by using benchmark values for the parameters of Table 1. To check for the robustness of our findings we study the sensitivity of our results using alternative values for the standard deviation of the innovation, holding all other parameters fixed. Then we vary the persistence of each shock, holding all other parameters at their benchmark values. We also check how expected growth changes when shocks' serial correlation changes, while their variance is fixed. Finally, we vary the labour supply coefficient $\eta$, the subjective discount factor $\beta$, the rate of capital depreciation $\delta$, and the steady-state employment level $L$.

\subsubsection{Monetary Shocks Volatility}

Table 2 shows that increased monetary policy variability results in lower growth and a lower level of equilibrium employment. First we notice that, given equation (27) and abstracting from the real shocks, up to a first order the rate of growth goes up if labour goes up as well. So we first focus on this variable to interpret this result. In particular, the employment rate will be lower the higher is $\eta$. Our intuitive explanation is built around the optimal condition for the nominal wage (11). We can see that for given price level and consumption, the wage is the ratio of the expected value of a convex function of employment and of the expected value of a linear function of employment. So for a given level of employment, if the variance of employment increases, then the numerator will increase more than the denominator, pushing up the target real wage, or in other terms, through labour demand, pushing down equilibrium employment. So we have 'target real wage effect', involving a negative 'employment effect'. Notice however that, by (3), labour demand is a convex function of the real wage, so that an increase in the variability of the real wage tends, through this mechanism, to increase employment. This is the 'labour demand effect'.

The sign of the relationship between nominal volatility and consumption growth tends to be positive for low values of the coefficient $\eta$. Intuitively, the lower is $\eta$ the 
weaker the 'target real wage effect' and the implied 'employment effect', as Table 2 shows. The sum of the positive 'precautionary saving effect' and 'labour demand effect' then prevails. Looking again at (27) from a different angle, we have to consider that the expression on the right hand side is concave in labour and convex in growth, so an increase in the variance of labour moves the expression down and an increase in the variance of growth moves it up, making it possible for labour and growth to move in opposite directions with increased uncertainty (in Table 2 this is seen to happen for $\eta=1.2)$.

Conversely, the higher $\eta$, the larger in absolute value are the negative effects produced by monetary volatility on the unconditional mean of consumption growth. In fact, the lower the FELS, the higher the positive response of the nominal wage to the variance of the monetary shock i.e. the 'target real wage effect', and, as a consequence, the stronger the negative 'employment' effect, which dominates the positive 'precautionary saving effect' and 'labour demand effect'.

Finally, we notice that the persistence of the monetary shock has no effect on the relationships derived, which is explained by the fact that in the model only money surprises have real effects. In fact this also explains the fact that an increase in the variance of the monetary shock has negligible effects on the variance of growth. As we will seen when the coefficient of autocorrelation is set to zero the effect of their variance on growth volatility is negligible for all shocks. If the model had featured for instance staggered wage contracts, monetary shocks would have had more persistent effects and money shocks volatility would have had bigger effects on growth volatility: including such mechanisms in the model is a direction for future research.

\subsubsection{Technological Shocks Volatility}

Table 3 shows that in the presence of technological variability uncertainty increases average consumption growth and average employment. This is partly due to the 
convexity of labour demand with respect not only to real wage, as described above, but also with respect to $b_{t}$, as easily readable from (3). These two 'labour demand effects' prevail over the 'target real wage effect', so employment on average goes up. The largest impact of uncertainty upon growth is observed for low levels of the parameter $\eta$ : when $\eta$ is high the 'target real wage effect' tends to dampen the 'labour demand effects' and the 'precautionary saving' effect.

We observe that changes in the variability of the innovation, $\sigma_{\varepsilon_{b}}$, have a larger impact on the unconditional mean of growth rates than changes in the persistence of the shock, $\rho_{b}$. Nevertheless, both sources of volatility have a monotonically increasing effect on the average growth rate. Table 3 also shows how expected growth changes when the autocorrelation coefficient in the exogenous state variable changes, while keeping its variance fixed. This means that even if technological uncertainty in itself increases growth, however a negative correlation between growth and its variance may be detected in the data. This shows that it could be important in empirical analysis to decompose total variability into a pure 'risk' element, due to the innovation variance, and the increase in persistence, which is a predictable element, a point raised in Wolf (2005).

\subsubsection{Fiscal Shocks Volatility}

The interplay between the various effects of uncertainty, i.e the positive ones (through precautionary savings and the convexity of labor demand with respect to the real wage) and the negative one (through the higher target real wage) is particularly difficult to disentangle in the case of fiscal shocks. Table 4 shows that consumption growth increases as fiscal variability rises if the FELS if is sufficiently high, and if the coefficient of autocorrelation of fiscal shocks is lower than 0.95 .

We notice however that varying the serial correlation of the fiscal shock has a non-linear effect on average growth rate: we observe first a positive, then a negative 
relationship. Similarly, even for a high FELS $(\eta=1.5)$, fixing the variance of the shock at its benchmark value, if the autocorrelation of the shocks is above 0.7 expected growth will be decreasing in $\rho_{u}$, while its standard deviation will be increasing so, as in the case of the technological shock, a negative correlation between growth and its variance will appear empirically even for configurations of parameters conductive to higher growth under uncertainty. This shows the importance in applied work to separate expected volatility from unexpected volatility.

\subsubsection{The Effect of the Frisch Elasticity of Labour}

From the above results it clearly emerges that the size of the Frisch (compensated) elasticity of labour supply is a crucial parameter in determining the effects of real and nominal volatility. We recall that available estimates from micro data vary widely, due to measurement errors and sample selection bias problems, but most surveys report a "consensus" estimate for labour supply elasticity of -0.1 for males, with the income effect being the double in absolute value of the substitution effect. Blundell and Macurdy (1999) and Borjas (2008) offer recent overviews of the literature. This would correspond to a value for $\eta$ equal to 11 . The elasticity of labour supply for females is estimated to be higher (see for instance Blau and Kahn, 2006). Aggregate models often assume elastic labor supply, despite the low estimates from empirical studies based on individual data. The explanation offered is that fluctuations of hours are mainly accounted for by participation rates, so that the important margin is the extensive rather than the intensive (see, for instance, Rogerson and Wallenius 2007 and Chang and Kim 2006). Given the ongoing debate on the issue, we offer results on a wide range of values of the FELS. Figures 1-3 plot the relationship between the unconditional mean of consumption growth, $E(g)$, and the standard deviation of each shock, for four different levels of the parameter $\eta$. In particular, in each plot we vary the standard deviation of the innovation, holding the serial correlation and all other 
parameters fixed at their benchmark levels.

For high values of the parameter $\eta$ we observe that uncertainty has a negative effect on growth in the case of money and fiscal shocks, while the positive effect is lowered by a high value of $\eta$ in the case of the technology shock. We also notice that the relationship between mean growth rates and volatility is monotonic for each shock.

\subsection{Volatility and Growth in a Competitive Labour Market}

Consider now the effects of uncertainty on average growth under competitive labour markets with flexible wages. Tables 5-6 present the effects of the volatility of the real shocks on the unconditional mean of consumption growth, $E(g)$, and on mean employment, $E(L)$.

Close inspection of the results reveals that in general the sign of the relationship between the volatility of the shocks and average consumption growth is not affected by the labour market wage setting mechanism, however the magnitude of the observed effects may change considerably.

Table 5 shows that the effects of uncertainty of the technology shock are still positive with a competitive labour market, but the size of the effects is systematically lower than in a monopolistic market with nominal rigidities.

When we vary the persistence of the technology shock, $\rho_{b}$, holding $\sigma_{b}$ and all other parameters fixed, again we observe a non-linearity, with expected growth and its volatility being negatively related for $\rho_{b}>0.7$.

Larger positive effects are instead observed under a competitive labour market when the source of economic fluctuation is given by fiscal policy (see Table 6): this confirm the result we found in the analytic setting. As seen in the case of nominal wage rigidities expected growth is lower than in a deterministic case for a high value of the shock autocorrelation. Again we study how expected growth changes when the autocorrelation coefficient in the fiscal shock changes, while keeping its variance 
fixed. Note that again increasing the autocorrelation coefficient of the exogenous fiscal process has a non-linear effect on the average growth rate $E(g)$.

Finally we observe that, as in the case of monopolistic wage setting, the effect of uncertainty on consumption growth varies with the parameter $\eta$ affecting the FELS. The lower the FELS, the lower the positive effect of a given amount of uncertainty upon growth. In particular, Figures 4-5 plot consumption growth rates as a function of the serial correlations for each shock when a higher value of $\eta$ is considered, keeping all other parameters constant. We observe that when volatility is due to the fiscal shock, for a lower FELS there is a wider gap between the effects on growth rates produced by uncertainty under monopolistic nominal wage setting and those observed in a competitive labour market. Unsurprisingly the role played by labour market institutions in affecting the relationship between growth and volatility tends to be higher, the lower the FELS.

\section{Concluding Remarks}

In this paper we explore the links between short-run (cyclical) phenomena and long-run technological trend of output. The study of the issue has important policy implications as it opens the possibility that stabilization policies affect the long-run performance of the economy, with cumulative effects.

The impact of volatility on economic growth has been the subject of considerable investigation in the empirical literature. However, the evidence provided on the variability-growth relationship is mixed, withe cross-section studies finding a negative correlation and time-series studies finding a positive correlation, especially when nominal volatility is jointly considered. Our results help in part to explain this evidence: in fact in the model presented the relationship between growth and volatility depends on the source of the stochastic fluctuations in the economy.

A key role is also played by the Frisch elasticity of labour supply and by labour 
market institutions. We observe that in general consumption growth is adversely affected by the volatility of the money supply shock, unless the Frisch elasticity of labour supply is low (but still consistent with available estimates). Conversely, the volatility of the technological shock has a positive impact on growth: however this will not always determine an observed positive correlation between growth and its standard deviation, unless the innovation variance is isolated from the predictable component of volatility. Finally, the volatility of government spending will have a negative effect on growth for low enough values of the Frisch elasticity and/or for a high enough degree of serial correlation in the process governing the shocks.

Coming to the effect of the organization of the labour market, we show that money volatility will have a negative effect on growth in the presence of nominal wage setting, while the effect of technology variability will be stronger and those of fiscal volatility weaker than with a competitive labour market.

Our analysis is intended to be a first step towards a deeper understanding of the interplay between short-run macroeconomic fluctuations and long-run growth. The study of the role of stabilising policies aimed at reducing stochastic fluctuations and promoting growth provides a fruitful direction for future research. From our analysis it clearly emerges, in fact, that there may exist a conflict between short-term stabilisation objectives and long-term growth depending on the source of the fluctuations.

\section{Appendix}

Derivation of (17): When $L_{t}=N_{t}$ using (10) we can rewrite (11) as: $\frac{(1-\beta) M_{t-1} \eta \lambda E_{t-1} L_{t}^{\eta}}{\alpha \mu E_{t-1} L_{t} a_{t}^{-1}}=$ $W_{t}$, while, combining (3) and (10) we get $W_{t}=\alpha b_{t} L_{t}^{\alpha-1} K_{t} \frac{(1-\beta) \gamma M_{t}}{\mu C_{t}}$. Eliminating $W_{t}$ from these two equations we get: $\frac{(1-\beta) M_{t-1} \eta \lambda E_{t-1} L_{t}^{\eta}}{\alpha \mu E_{t-1} L_{t} a_{t}^{-1}}=\alpha b_{t} L_{t}^{\alpha-1} K_{t} \frac{(1-\beta) \gamma M_{t}}{\mu C_{t}}$ which gives us (17) considering: $M_{t}=a_{t} M_{t-1}$. 
Derivation of (19): When $\delta=100 \%$ we have: $K_{t+2}+C_{t+1}+G_{t+1}=Y_{t+1}=$ $K_{t+1}\left(1+R_{t+1}\right)(1-\alpha)^{-1}$ where the second equality comes from (4). We can then write (8) as:

$$
C_{t}^{-1} K_{t+1}=\beta E_{t} C_{t+1}^{-1}\left(K_{t+2}+C_{t+1}+G_{t+1}\right)(1-\alpha)
$$

When $u_{t}$ is i.i.d. (and uncorrelated with each other) we can write $E_{t} u_{t+i} \equiv u$ for all $i=1,2 . . n$. Iterating and considering the transversality condition we then have:

$$
C_{t}=\frac{1-\varkappa}{\varkappa(1+u)} K_{t+1}
$$

where $\varkappa \equiv \alpha(1-\beta)$. Using: $C_{t}\left(1+u_{t}\right)+K_{t+1}=Y_{t}$ we can easily derive (19) and:

$$
C_{t}=\frac{1-\varkappa}{\left(1+u_{t}\right)(1-\varkappa)+\varkappa(1+u)} Y_{t}
$$

Derivation of (20): Combining (10) and (43) we have:

$$
M_{t}(1-\beta) \mu^{-1}=\frac{(1-\varkappa)}{\gamma\left[\left(1+u_{t}\right)(1-\varkappa)+\varkappa(1+u)\right]} Y_{t} P_{t} .
$$

Using (3) and rearranging we have:

$$
L_{t}=\frac{\alpha \gamma M_{t}(1-\beta)\left[\left(1+u_{t}\right)(1-\varkappa)+\varkappa(1+u)\right]}{\mu(1-\varkappa) W_{t}} .
$$

We can then compute:

$$
\eta \lambda L_{t}^{\eta}=\eta \lambda\left(\frac{\gamma \varkappa M_{t}\left[\left(1+u_{t}\right)(1-\varkappa)+\varkappa(1+u)\right]}{\mu(1-\varkappa) W_{t}}\right)^{\eta},
$$

and

$$
\eta \lambda E_{t-1} L_{t}^{\eta}=\eta \lambda E_{t-1}\left(\frac{M_{t} \varkappa\left[\left(1+u_{t}\right)(1-\varkappa) \gamma_{t}+\varkappa \gamma(1+u)\right]}{\mu(1-\varkappa) W_{t}}\right)^{\eta} .
$$


Using (43), (11) can be rewritten as:

$$
\begin{aligned}
\eta \lambda E_{t-1} L_{t}^{\eta} & =\alpha E_{t-1} W_{t} L_{t}\left(Y_{t} P_{t}\right)^{-1}(1-\varkappa)^{-1} \gamma\left[\left(1+u_{t}(1-\varkappa)+\varkappa(1+u)\right]\right. \\
& =\frac{\alpha^{2}}{1-a} \gamma E_{t-1}\left[\left(1+u_{t}(1-\varkappa) \gamma+\varkappa(1+u)\right] .\right.
\end{aligned}
$$

The second equality is obtained using (3). Finally, using the assumed properties of the distribution of the shock $u_{t}$ we have $\eta \lambda E_{t-1} L_{t}^{\eta}=\frac{\alpha^{2} \gamma(1+u)}{1-\varkappa}$, using which in (45) we arrive to:

$$
W_{t}^{\eta} \frac{\alpha^{2} \gamma(1+u)}{1-\varkappa}=\eta \lambda E_{t-1}\left(\frac{\gamma M_{t} \varkappa\left[\left(1+u_{t}\right)(1-\varkappa)+\varkappa(1+u)\right]}{\mu(1-\varkappa)}\right)^{\eta} .
$$

To proceed further we assume $\eta=1 .^{8}$ Assuming $\rho_{a}=0$ and $\rho_{\lambda}=0$, the expression above becomes:

$$
W_{t}=\frac{M_{t-1} \varkappa \lambda a}{\alpha^{2} \mu}
$$

This, using (44), can be rewritten as (20).

Proof of Proposition 1: Using the production function to write $Y_{t+1}=K_{t+1} b_{t+1} L_{t+1}^{\alpha}$ and the expression for $Y_{t}$ in terms of $K_{t+1}$ given by (19), we can write the rate of growth of output as:

$$
\frac{Y_{t+1}}{Y_{t}}=\frac{b_{t+1} L_{t+1}^{\alpha} \varkappa(1+u)}{\left(1+u_{t}\right)(1-\varkappa)+\varkappa(1+u)},
$$

Substituting (20) in (46) we find (21).

Derivation of (23): If we combine (43) and (12), while considering that labour income is $\alpha$ times total income, we get (23).

Proof of Proposition 2: Substituting (23) in (46) we have (24).

\footnotetext{
${ }^{8}$ Another possibility, pursued in Blackburn and Pelloni (2005) is to treat $u_{t}$ as constant through time.
} 


\section{References}

[1] Aghion P. and A. Banerjee, 2005. Volatility and Growth. Oxford University Press, Oxford.

[2] Aizenman J. and B. Pinto, 2005. Managing economic volatility and crises: A practitioner's guide oveview, in Managing Economic Volatility and Crises: A Practitioner's Guide (Aizenman J. and B. Pinto, eds). Cambridge University Press, Cambridge.

[3] Andreou E., A. Pelloni and M. Sensier, 2008. Is volatility good for growth? Evidence from the G7. Centre for Growth and Business Cycle Research Discussion Paper Series, University of Manchester, No. 97.

[4] Andrés J. and I. Hernando, 1997. Does inflation harm economic growth? Evidence for the OECD. NBER Working Paper, No. 6062.

[5] Attanasio O.P. and G. Weber, 1993. Consumption growth, the interest rate and aggregation.Review of Economic Studies, 60, 631-49.

[6] Barlevy G., 2007. On the Cyclicality of research and development. American Economic Review, 97, 1131-1164.

[7] Barro R.J., 1997. Determinants of Economic Growth: A Cross-country Empirical Study. MIT Press, Cambridge, MA.

[8] Barro R.J., 2001. Human capital and growth. American Economic Review, 91, $12-17$.

[9] Beaudry P. and E. van Wincoop, 1996. The intertemporal elasticity of substitution: An exploration using a US panel of state data. Economica, 63, 495-512.

[10] Bénassy J-P., 1995. Money and wage contracts in an optimising model of the business cycle. Journal of Monetary Economics, 35, 303-315.

[11] Bewley T. F., 1999. Why wages don't fall during a recession? Harvard University Press, Cambridge, MA, and London.

[12] Blackburn K., 1999. Can stabilisation policy reduce long-run growth? Economic Journal, 109, 67-77.

[13] Blackburn K. and R. Galindev, 2003. Growth, volatility and learning. Economics Letters, 79, 417-421.

[14] Blackburn K. and A. Pelloni, 2004. On the relationship between growth and volatility. Economics Letters, 83, 123-127.

[15] Blackburn K. and A. Pelloni, 2005. Growth, cycles, and stabilization policy. Oxford Economic Papers, 57, 262-282. 
[16] Blackburn K. and D. Varvarigos, 2008. Human capital accumulation and output growth in a stochastic environment. Economic Theory, forthcoming.

[17] Blau F. and L. Kahn, 2006. Changes in the labour supply behavior of married women 1980-2000. IZA Working Paper, No. 2180.

[18] Blundell R. and T. Macurdy, 1999. Labor supply: A review of alternative approaches, in Handbook of Labor Economics (Ashenfelter O. and D. Card, eds), Elsevier, vol. 3, chapter 27, 1559-1695.

[19] Borjas G.J., 2008. Labour Economics. McGraw-Hill, London.

[20] Chang Y. and S. Kim, 2006. From individual to aggregate labor supply: A quantitative analysis based on a heterogeneous agent macroeconomy. International Economic Review, 47, 1-27.

[21] Canton E., 2002. Business cycles in a two-sector model of endogenous growth. Economic Theory, 19, 477-492.

[22] Caporale T. and B. McKiernan, 1996. The relationship between output variability and growth: evidence from post-war UK data. Scottish Journal of Political Economy, 43, 229-236.

[23] Cooper R. and A. Johri, 1999. Learning-by-doing and aggregate fluctuations. NBER Working Paper, No. 6898.

[24] Dawson J.W. and E. F. Stephenson, 1997. The link between volatility and growth. Evidence from the States. Economics Letters, 55, 365-9.

[25] de Hek P. 1999. On Endogenous growth under uncertainty. International Economic Review, 40, 727-744.

[26] Dickens W.T., L. Goette, E. L. Groshen, S. Holden, J. Messina, M. E. Schweitzer, J. Turunen and M. E. Ward, 2007. How wages change: Micro evidence from the international wage flexibility project. Journal of Economic Perspectives, 21, 195214 .

[27] Dotsey M. and P. D. Sarte, 2000. Inflation uncertainty and growth in a cash-inadvance economy. Journal of Monetary Economics, 45, 631-655.

[28] Elder J. 2004. Another perspective on the effects of inflation uncertainty. Journal of Money, Credit and Banking, 36, 911-928.

[29] Evans L. and T. Kenc 2003. Welfare cost of monetary and fiscal policy shocks. Macroeconomic Dynamics, 7, 212-238

[30] Fischer S., 1977. Long-term contracts, rational expectations and the optimal money supply rule. Journal of Political Economy, 85, 163-190. 
[31] Fountas S., M. Karanasos and J. Kim, 2006. Inflation uncertainty, output growth uncertainty and macroeconomic performance. Oxford Bulletin of Economics and Statistics, 68, 319-343.

[32] Gaggl P. and S. Steindl, 2007. Business cycles and growth: A survey. WIFO Working Papers, No. 308.

[33] Galí J., D. López-Salido and J. Vallés, 2007. Understanding the effects of government spending on consumption. Journal of the European Economic Association, 5, 227-270.

[34] Goodfriend M., 2002. Interest on reserves and monetary policy. Economic Policy Review, May, 77-84.

[35] Gray J., 1976. Wage indexation: a macroeconomic approach. Journal of Monetary Economics, 2, 221-235.

[36] Grier K.B., O.T. Henry, N. Olekalns and K. Shields, 2004. The asymmetric effect of uncertainty on inflation and output growth. Journal of Applied Econometrics, $19,551-565$.

[37] Grier K.B. and M. J. Perry, 2000. The effects of real and nominal uncertainty on inflation and output growth: some Garch-M evidence. Journal of Applied Econometrics, 15, 45-58.

[38] Grinols E.L. and S.J Turnovsky, 1993. Risk, the financial market, and macroeconomic equilibrium. Journal of Economic Dynamics and Control, 17, 1-36.

[39] Hall R.E., 1988. Intertemporal Substitution in Consumption. Journal of Political Economy, 96, 339-357.

[40] Hnatkovska V. and N. Loayza, 2005. Volatility and growth, in Managing Economic Volatility and Crises: A Practitioner's Guide (Aizenman J. and B. Pinto, eds). Cambridge University Press, Cambridge.

[41] Jones L.E., R.E. Manuelli, H. Siu and E. Stacchetti, 2005. Fluctuations in convex models of endogenous growth, I: Growth effects. Review of Economic Dynamics, $8,780-804$.

[42] Jovanovic B. and P. Rousseau, 2002. Moore's law and learning by doing. Review of Economic Dynamics, 5, 346-375.

[43] Judson R. and A. Orphanides, 1999. Inflation, volatility and growth. International Finance, 2, 117-138.

[44] Kim J., S. Kim, E. Schaumburg and C. A. Sims, 2003. Calculating and using second order accurate solutions of discrete time dynamic equilibrium models. Finance and Economics Discussion Series, No. 61, Board of Governors of the Federal Reserve System (U.S.). 
[45] King R.G. and S. Rebelo, 1999. Resuscitating real business cycles, in Handbook of Macroeconomics (Taylor J. B. and M. Woodford, eds), Elsevier, vol. 1, chapter 14, 927-1007.

[46] Kose M.A., E.S. Prasad and M.E. Terrones, 2005. Growth and volatility in an era of globalization. IMF Staff Papers, 52, Special Issue, 31-63.

[47] Lombardo G. and A. Sutherland, 2007. Computing second-order-accurate solutions for rational expectation models using linear solution methods. Journal of Economic Dynamics and Control, 31, 515-530.

[48] Martin P. and C.A. Rogers, 1997. Stabilisation policy, learning-by-doing and economic growth. Oxford Economic Papers, 49, 152-166.

[49] Martin P. and C.A. Rogers, 2000. Long-term growth and short-term economic instability. European Economic Review, 44, 359-381.

[50] Mulligan C.B. 2004. What do aggregate consumption Euler equations say about the capital-income tax burden?. American Economic Review, 94, 166-170.

[51] Nelson C. R. and C. I. Plosser, 1982. Trends and random walks in macroeconomic time series: some evidence and implications. Journal of Monetary Economics, 10, 139-162.

[52] Pelloni A., 1997. Nominal shocks, endogenous growth and the business cycle. Economic Journal, 107, 467-474.

[53] Ramey G. and V.A. Ramey, 1995. Cross-country evidence on the link between volatility and growth. American Economic Review, 85, 1138-1152.

[54] Rogerson R. and J. Wallenius, 2007. Micro and macro elasticities in a life-cycle model with taxes. NBER Working Paper, No. 13017.

[55] Romer P.M., 1986. Increasing returns and long-run growth. Journal of Political Economy, 94, 1002-1037.

[56] Schmitt-Grohé S. and M. Uribe, 2004. Solving dynamic general equilibrium models using a second-order approximation to the policy function. Journal of Economic Dynamics and Control, 28, 755-775.

[57] Schmitt-Grohé S. and M. Uribe, 2007. Optimal simple and implementable monetary and fiscal rules. Journal of Monetary Economics, 54, 1702-1725.

[58] Sims C.A., 2001. Solving linear rational expectations models. Computational Economics, 20, 1-20.

[59] Temple J., 2000. Inflation and growth: stories short and tall. Journal of Economic Surveys, 14, 395-426. 
[60] Thornton R. and P. Thompson, 2001. Learning from experience and learning from others: An exploration of learning and spillovers in wartime shipbuilding. American Economic Review, 91, 1350-1368.

[61] Turnovsky S.J., 2000. Government policy in a stochastic growth model with elastic labor supply. Journal of Public Economic Theory, 2, 389-433.

[62] Turnovsky S. J. and P. Chattopadhyay, 2003. Volatility and growth in developing economies: Some numerical results and empirical evidence. Journal of International Economics, 59, 267-295.

[63] Varvarigos D., 2008. Inflation, variability, and the evolution of human capital in a model with transactions costs. Economics Letters, 98, 320-326.

[64] Vissing -Jørgensen and O. Attanasio 2003. Stock-market participation, intertemporal substitution, and risk-aversion. American Economic Review, 93, 383-391.

[65] Walde K. and U. Woitek, 2004. R\&D expenditure in G7 countries and the implications for endogenous fluctuations and growth. Economics Letters, 82, 91-97.

[66] Wolf H., 2005. Volatility: definitions and consequences, in Managing Economic Volatility and Crises: A Practitioner's Guide (Aizenman J. and B. Pinto, eds). Cambridge University Press, Cambridge. 
Table 1: Baseline Calibration

\begin{tabular}{lll}
\hline \hline \multicolumn{3}{l}{ Parameters } \\
\hline$\beta$ & 0.96 & Subjective discount factor \\
$\delta$ & 0.1 & Depreciation rate \\
$\alpha$ & 0.7 & Cost share of labour \\
$\gamma$ & 1 & Preference parameter \\
$\eta$ & 1.5 & Preference parameter \\
$\rho_{a}$ & 0.69 & Autoregressive parameter in the monetary shock \\
$\rho_{b}$ & 0.85 & Autoregressive parameter in the technology shock \\
$\rho_{u}$ & 0.87 & Autoregressive parameter in the fiscal shock \\
$\sigma_{\varepsilon_{a}}$ & 0.0190 & Standard deviation of the innovation $\varepsilon_{a}$ \\
$\sigma_{\varepsilon_{b}}$ & 0.0212 & Standard deviation of the innovation $\varepsilon_{b}$ \\
$\sigma_{\varepsilon_{u}}$ & 0.0102 & Standard deviation of the innovation $\varepsilon_{u}$ \\
\hline Ratios over Capital and Steady-State Values \\
\hline$m_{p}$ & 0.26 & Real money balances \\
$s$ & 0.1 & Government spending \\
$\pi$ & 1.04 & Inflation \\
$L$ & 0.2 & Labour supply \\
$g$ & $2 \%$ & Consumption growth rate \\
\hline \hline
\end{tabular}


Table 2: Volatility of the Monetary Shock under Monopolistic Nominal Wage Setting

\begin{tabular}{|c|c|c|c|c|c|c|c|}
\hline Benchmark & $\begin{array}{c}\sigma_{\varepsilon_{a}} \\
0.019\end{array}$ & $\begin{array}{c}\rho_{a} \\
0.69 \\
\end{array}$ & $\begin{array}{c}\sigma_{a} \\
0.0263\end{array}$ & $\begin{array}{c}E(g) \\
1.9995\end{array}$ & $\begin{array}{c}\sigma_{g} \\
0.0000\end{array}$ & $\begin{array}{c}E(L) \\
0.1999\end{array}$ & $\begin{array}{c}\sigma_{L} \\
0.0000 \\
\end{array}$ \\
\hline \multirow[t]{7}{*}{ The effect of $\sigma_{\varepsilon_{a}}$ on growth rates } & $\sigma_{\varepsilon_{a}}$ & $\rho_{a}$ & $\sigma_{a}$ & $\overline{E(g)}$ & $\sigma_{g}$ & $\overline{E E(L)}$ & $\sigma_{L}$ \\
\hline & 0.01 & 0.69 & 0.0138 & 1.9999 & 0.0000 & 0.2000 & 0.0000 \\
\hline & 0.03 & 0.69 & 0.0415 & 1.9988 & 0.0000 & 0.1998 & 0.0000 \\
\hline & 0.05 & 0.69 & 0.0691 & 1.9966 & 0.0000 & 0.1994 & 0.0000 \\
\hline & 0.08 & 0.69 & 0.1105 & 1.9913 & 0.0000 & 0.1985 & 0.0000 \\
\hline & 0.10 & 0.69 & 0.1382 & 1.9864 & 0.0000 & 0.1976 & 0.0000 \\
\hline & 0.15 & 0.69 & 0.2072 & 1.9694 & 0.0000 & 0.1946 & 0.0000 \\
\hline \multirow[t]{4}{*}{ The effect of $\rho_{a}$ on growth rates } & $\sigma_{\varepsilon_{a}}$ & $\rho_{a}$ & $\sigma_{a}$ & $E(g)$ & $\sigma_{g}$ & $E(L)$ & $\sigma_{L}$ \\
\hline & 0.019 & 0 & 0.0190 & 1.9995 & 0.0000 & 0.1999 & 0.0000 \\
\hline & 0.019 & 0.50 & 0.0219 & 1.9995 & 0.0000 & 0.1999 & 0.0000 \\
\hline & 0.019 & 0.90 & 0.0436 & 1.9995 & 0.0000 & 0.1999 & 0.0000 \\
\hline \multirow{4}{*}{$\begin{array}{l}\text { The effect of } \rho_{a} \text { on growth rates } \\
\text { for benchmark variance }\end{array}$} & $\sigma_{\varepsilon_{a}}$ & $\rho_{a}$ & $\sigma_{a}$ & $E(g)$ & $\sigma_{g}$ & $E(L)$ & $\sigma_{L}$ \\
\hline & 0.0263 & 0 & 0.0263 & 1.9995 & 0.0000 & 0.1999 & 0.0000 \\
\hline & 0.0227 & 0.50 & 0.0263 & 1.9995 & 0.0000 & 0.1999 & 0.0000 \\
\hline & 0.0114 & 0.90 & 0.0263 & 1.9995 & 0.0000 & 0.1999 & 0.0000 \\
\hline \multirow{4}{*}{$\begin{array}{l}\text { The effect of } \eta \text { on the relationship } \\
\text { between volatility and growth }\end{array}$} & & & & $\overline{E E(g)}$ & $\sigma_{g}$ & $\overline{E E(L)}$ & $\sigma_{L}$ \\
\hline & $\eta=1.2$ & & & 2.0012 & 0.0000 & 0.1999 & 0.0000 \\
\hline & $\eta=3$ & & & 1.9912 & 0.0000 & 0.1998 & 0.0000 \\
\hline & $\eta=5$ & & & 1.9802 & 0.0000 & 0.1996 & 0.0000 \\
\hline \multirow[t]{7}{*}{ Sensitivity } & & & & $E(g)$ & $\sigma_{g}$ & $\overline{E E(L)}$ & $\sigma_{L}$ \\
\hline & $\beta=0.9$ & & & 1.9995 & 0.0000 & 0.1999 & 0.0000 \\
\hline & $\beta=0.9$ & & & 1.9995 & 0.0000 & 0.1999 & 0.0000 \\
\hline & $\delta=0.0$ & & & 1.9993 & 0.0000 & 0.1999 & 0.0000 \\
\hline & $\delta=0.1$ & & & 1.9997 & 0.0000 & 0.1999 & 0.0000 \\
\hline & $L=0.1$ & & & 1.9995 & 0.0000 & 0.1699 & 0.0000 \\
\hline & $L=0.3$ & & & 1.9995 & 0.0000 & 0.2999 & 0.0000 \\
\hline
\end{tabular}


Table 3: Volatility of the Technology Shock under Monopolistic Nominal Wage Setting

\begin{tabular}{|c|c|c|c|c|c|c|c|}
\hline Benchmark & $\begin{array}{c}\sigma_{\varepsilon_{b}} \\
0.0212 \\
\end{array}$ & $\begin{array}{c}\rho_{b} \\
0.85 \\
\end{array}$ & $\begin{array}{c}\sigma_{b} \\
0.0402 \\
\end{array}$ & $\begin{array}{c}E(g) \\
2.0112\end{array}$ & $\begin{array}{c}\sigma_{g} \\
0.0037 \\
\end{array}$ & $\begin{array}{c}E(L) \\
0.2001 \\
\end{array}$ & $\begin{array}{c}\sigma_{L} \\
0.0009 \\
\end{array}$ \\
\hline \multirow[t]{7}{*}{ The effect of $\sigma_{\varepsilon_{b}}$ on growth rates } & $\sigma_{\varepsilon_{b}}$ & $\rho_{b}$ & $\sigma_{b}$ & $E(g)$ & $\sigma_{g}$ & $E(L)$ & $\sigma_{L}$ \\
\hline & 0.01 & 0.85 & 0.0190 & 2.0025 & 0.0017 & 0.2000 & 0.0004 \\
\hline & 0.04 & 0.85 & 0.0759 & 2.0398 & 0.0070 & 0.2002 & 0.0017 \\
\hline & 0.06 & 0.85 & 0.1139 & 2.0895 & 0.0105 & 0.2005 & 0.0026 \\
\hline & 0.08 & 0.85 & 0.1519 & 2.1592 & 0.0140 & 0.2009 & 0.0035 \\
\hline & 0.10 & 0.85 & 0.1898 & 2.2487 & 0.0174 & 0.2014 & 0.0043 \\
\hline & 0.15 & 0.85 & 0.2847 & 2.5596 & 0.0262 & 0.2031 & 0.0065 \\
\hline \multirow[t]{8}{*}{ The effect of $\rho_{b}$ on growth rates } & $\sigma_{\varepsilon_{b}}$ & $\rho_{b}$ & $\sigma_{b}$ & $E(g)$ & $\sigma_{g}$ & $E(L)$ & $\sigma_{L}$ \\
\hline & 0.021 & 0 & 0.0212 & 2.0054 & 0.0000 & 0.2001 & 0.0000 \\
\hline & 0.021 & 0.10 & 0.0213 & 2.0057 & 0.0003 & 0.2001 & 0.0001 \\
\hline & 0.021 & 0.30 & 0.0222 & 2.0064 & 0.0008 & 0.2001 & 0.0004 \\
\hline & 0.021 & 0.50 & 0.0245 & 2.0075 & 0.0015 & 0.2001 & 0.0006 \\
\hline & 0.021 & 0.70 & 0.0297 & 2.0092 & 0.0024 & 0.2001 & 0.0008 \\
\hline & 0.021 & 0.95 & 0.0679 & 2.0131 & 0.0065 & 0.2000 & 0.0009 \\
\hline & 0.021 & 0.99 & 0.1503 & 2.0142 & 0.0146 & 0.2000 & 0.0013 \\
\hline \multirow{9}{*}{$\begin{array}{l}\text { The effect of } \rho_{b} \text { on growth rates } \\
\text { for benchmark variance }\end{array}$} & $\sigma_{\varepsilon_{b}}$ & $\rho_{b}$ & $\sigma_{b}$ & $E(g)$ & $\sigma_{g}$ & $E(E(L)$ & $\sigma_{L}$ \\
\hline & 0.0402 & 0 & 0.0402 & 2.0195 & 0.0000 & 0.2003 & 0.0000 \\
\hline & 0.0400 & 0.10 & 0.0402 & 2.0203 & 0.0005 & 0.2003 & 0.0003 \\
\hline & 0.0384 & 0.30 & 0.0402 & 2.0211 & 0.0015 & 0.2002 & 0.0008 \\
\hline & 0.0369 & 0.40 & 0.0402 & 2.0210 & 0.0020 & 0.2002 & 0.0009 \\
\hline & 0.0349 & 0.50 & 0.0402 & 2.0203 & 0.0025 & 0.2002 & 0.0011 \\
\hline & 0.0287 & 0.70 & 0.0402 & 2.0169 & 0.0033 & 0.2001 & 0.0011 \\
\hline & 0.0175 & 0.90 & 0.0402 & 2.0083 & 0.0038 & 0.2000 & 0.0008 \\
\hline & 0.0057 & 0.99 & 0.0402 & 2.0010 & 0.0039 & 0.2000 & 0.0003 \\
\hline \multirow{4}{*}{$\begin{array}{l}\text { The effect of } \eta \text { on the relationship } \\
\text { between volatility and growth }\end{array}$} & & & & $E(g)$ & $\sigma_{g}$ & $E(L)$ & $\sigma_{L}$ \\
\hline & $\eta=1.2$ & & & 2.0117 & 0.0038 & 0.2001 & 0.0012 \\
\hline & $\eta=3$ & & & 2.0101 & 0.0034 & 0.2001 & 0.0004 \\
\hline & $\eta=5$ & & & 2.0094 & 0.0033 & 0.2001 & 0.0002 \\
\hline \multirow[t]{7}{*}{ Sensitivity } & \multirow{2}{*}{\multicolumn{3}{|c|}{$\beta=0.95$}} & $E(g)$ & $\sigma_{g}$ & $E(L)$ & $\sigma_{L}$ \\
\hline & & & & 2.0095 & 0.0036 & 0.2001 & 0.0008 \\
\hline & \multicolumn{3}{|c|}{$\beta=0.97$} & 2.0126 & 0.0037 & 0.2001 & 0.0010 \\
\hline & \multicolumn{3}{|c|}{$\delta=0.075$} & 2.0152 & 0.0038 & 0.2001 & 0.0013 \\
\hline & \multicolumn{3}{|c|}{$\delta=0.125$} & 2.0085 & 0.0036 & 0.2000 & 0.0007 \\
\hline & \multicolumn{3}{|c|}{$L=0.17$} & 2.0089 & 0.0033 & 0.1700 & 0.0007 \\
\hline & \multicolumn{3}{|c|}{$L=0.3$} & 2.0197 & 0.0049 & 0.3002 & 0.0018 \\
\hline
\end{tabular}


Table 4: Volatility of the Fiscal Shock under Monopolistic Nominal Wage Setting

\begin{tabular}{|c|c|c|c|c|c|c|c|}
\hline Benchmark & $\begin{array}{c}\sigma_{\varepsilon_{u}} \\
0.0102\end{array}$ & $\begin{array}{c}\rho_{u} \\
0.87\end{array}$ & $\begin{array}{c}\sigma_{u} \\
0.0206\end{array}$ & $\begin{array}{c}E(g) \\
2.0003\end{array}$ & $\begin{array}{c}\sigma_{g} \\
0.0008\end{array}$ & $\begin{array}{c}E(L) \\
0.2000\end{array}$ & $\begin{array}{c}\sigma_{L} \\
0.0016\end{array}$ \\
\hline \multirow[t]{7}{*}{ The effect of $\sigma_{\varepsilon_{u}}$ on growth rates } & $\sigma_{\varepsilon_{u}}$ & $\rho_{u}$ & $\sigma_{u}$ & $E(g)$ & $\sigma_{g}$ & $E(L)$ & $\sigma_{L}$ \\
\hline & 0.005 & 0.87 & 0.0101 & 2.0001 & 0.0004 & 0.2000 & 0.0008 \\
\hline & 0.03 & 0.87 & 0.0608 & 2.0028 & 0.0025 & 0.1999 & 0.0046 \\
\hline & 0.05 & 0.87 & 0.1014 & 2.0076 & 0.0042 & 0.1998 & 0.0077 \\
\hline & 0.07 & 0.87 & 0.1420 & 2.0150 & 0.0059 & 0.1996 & 0.0108 \\
\hline & 0.10 & 0.87 & 0.2028 & 2.0306 & 0.0084 & 0.1992 & 0.0155 \\
\hline & 0.125 & 0.87 & 0.2535 & 2.0477 & 0.0105 & 0.1987 & 0.0194 \\
\hline \multirow[t]{8}{*}{ The effect of $\rho_{u}$ on growth rates } & $\sigma_{\varepsilon_{u}}$ & $\rho_{u}$ & $\sigma_{u}$ & $E(g)$ & $\sigma_{g}$ & $E(L)$ & $\sigma_{L}$ \\
\hline & 0.010 & 0 & 0.0102 & 2.0001 & 0.0000 & 0.2000 & 0.0000 \\
\hline & 0.010 & 0.10 & 0.0102 & 2.0001 & 0.0000 & 0.2000 & 0.0000 \\
\hline & 0.010 & 0.30 & 0.0107 & 2.0002 & 0.0000 & 0.2000 & 0.0002 \\
\hline & 0.010 & 0.50 & 0.0117 & 2.0003 & 0.0002 & 0.2000 & 0.0003 \\
\hline & 0.010 & 0.70 & 0.0142 & 2.0003 & 0.0004 & 0.2000 & 0.0007 \\
\hline & 0.010 & 0.95 & 0.0326 & 1.9998 & 0.0016 & 0.1980 & 0.0030 \\
\hline & 0.010 & 0.99 & 0.0721 & 1.9951 & 0.0040 & 0.1930 & 0.0073 \\
\hline \multirow{10}{*}{$\begin{array}{l}\text { The effect of } \rho_{u} \text { on growth rates } \\
\text { for benchmark variance }\end{array}$} & $\sigma_{\varepsilon_{u}}$ & $\rho_{u}$ & $\sigma_{u}$ & $E(g)$ & $\sigma_{g}$ & $E(L)$ & $\sigma_{L}$ \\
\hline & 0.0206 & 0 & 0.0206 & 2.0005 & 0.0000 & 0.2000 & 0.0000 \\
\hline & 0.0205 & 0.10 & 0.0206 & 2.0006 & 0.0000 & 0.2000 & 0.0001 \\
\hline & 0.0197 & 0.30 & 0.0206 & 2.0007 & 0.0002 & 0.2000 & 0.0003 \\
\hline & 0.0179 & 0.50 & 0.0206 & 2.0008 & 0.0003 & 0.2000 & 0.0006 \\
\hline & 0.0165 & 0.60 & 0.0206 & 2.0008 & 0.0004 & 0.2000 & 0.0008 \\
\hline & 0.0147 & 0.70 & 0.0206 & 2.0007 & 0.0006 & 0.2000 & 0.0010 \\
\hline & 0.0124 & 0.80 & 0.0206 & 2.0005 & 0.0010 & 0.2000 & 0.0013 \\
\hline & 0.0090 & 0.90 & 0.0206 & 2.0002 & 0.0010 & 0.2000 & 0.0017 \\
\hline & 0.0029 & 0.99 & 0.0206 & 1.9996 & 0.0011 & 0.2000 & 0.0021 \\
\hline \multirow{4}{*}{$\begin{array}{l}\text { The effect of } \eta \text { on the relationship } \\
\text { between volatility and growth }\end{array}$} & & & & $\overline{E E(g)}$ & $\sigma_{g}$ & $\overline{E E(L)}$ & $\sigma_{L}$ \\
\hline & $\eta=1.2$ & & & 2.0003 & 0.0011 & 0.2000 & 0.0020 \\
\hline & $\eta=3$ & & & 1.9998 & 0.0004 & 0.19998 & 0.0007 \\
\hline & $\eta=5$ & & & 1.9988 & 0.0002 & 0.19996 & 0.0004 \\
\hline \multirow[t]{7}{*}{ Sensitivity } & & & & $E(g)$ & $\sigma_{g}$ & $E(L)$ & $\sigma_{L}$ \\
\hline & \multicolumn{3}{|c|}{$\beta=0.95$} & 2.0003 & 0.0001 & 0.2000 & 0.0017 \\
\hline & \multicolumn{3}{|c|}{$\beta=0.97$} & 2.0003 & 0.0008 & 0.2000 & 0.0015 \\
\hline & \multicolumn{3}{|c|}{$\delta=0.075$} & 2.0004 & 0.0007 & 0.2000 & 0.0015 \\
\hline & \multicolumn{3}{|c|}{$\delta=0.125$} & 2.0003 & 0.0010 & 0.2000 & 0.0017 \\
\hline & \multicolumn{3}{|c|}{$L=0.17$} & 2.0003 & 0.0008 & 0.1700 & 0.0013 \\
\hline & \multicolumn{3}{|c|}{$L=0.3$} & 2.0003 & 0.0008 & 0.3000 & 0.0023 \\
\hline
\end{tabular}


Table 5: Volatility of the Technology Shock under Competitive Labour Market

\begin{tabular}{|c|c|c|c|c|c|c|c|}
\hline Benchmark & $\begin{array}{c}\sigma_{\varepsilon_{b}} \\
0.021\end{array}$ & $\begin{array}{c}\rho_{b} \\
0.85\end{array}$ & $\begin{array}{c}\sigma_{b} \\
0.0402\end{array}$ & $\begin{array}{c}E(g) \\
2.0112\end{array}$ & $\begin{array}{c}\sigma_{g} \\
0.0037\end{array}$ & $\begin{array}{c}E(L) \\
0.20006\end{array}$ & $\begin{array}{c}\sigma_{L} \\
0.0009\end{array}$ \\
\hline \multirow[t]{7}{*}{ The effect of $\sigma_{\varepsilon_{b}}$ on growth rates } & $\sigma_{\varepsilon_{b}}$ & $\rho_{b}$ & $\sigma_{b}$ & $E(g)$ & $\sigma_{g}$ & $E(L)$ & $\sigma_{L}$ \\
\hline & 0.01 & 0.85 & 0.0190 & 2.0022 & 0.0017 & 0.2000 & 0.0004 \\
\hline & 0.04 & 0.85 & 0.0759 & 2.0353 & 0.0070 & 0.2002 & 0.0017 \\
\hline & 0.06 & 0.85 & 0.1139 & 2.0794 & 0.0105 & 0.2005 & 0.0026 \\
\hline & 0.08 & 0.85 & 0.1519 & 2.1411 & 0.0140 & 0.2008 & 0.0035 \\
\hline & 0.10 & 0.85 & 0.1898 & 2.2205 & 0.0174 & 0.2012 & 0.0043 \\
\hline & 0.15 & 0.85 & 0.2847 & 2.4962 & 0.0262 & 0.2029 & 0.0065 \\
\hline \multirow[t]{8}{*}{ The effect of $\rho_{b}$ on growth rates } & $\sigma_{\varepsilon_{b}}$ & $\rho_{b}$ & $\sigma_{b}$ & $E(g)$ & $\sigma_{g}$ & $E(L)$ & $\sigma_{L}$ \\
\hline & 0.021 & 0 & 0.0212 & 2.0035 & 0.0000 & 0.20007 & 0.0000 \\
\hline & 0.021 & 0.10 & 0.0213 & 2.0038 & 0.0003 & 0.20007 & 0.0001 \\
\hline & 0.021 & 0.30 & 0.0222 & 2.0045 & 0.0008 & 0.20007 & 0.0004 \\
\hline & 0.021 & 0.50 & 0.0245 & 2.0057 & 0.0015 & 0.20007 & 0.0006 \\
\hline & 0.021 & 0.70 & 0.0297 & 2.0075 & 0.0024 & 0.20006 & 0.0008 \\
\hline & 0.021 & 0.95 & 0.0679 & 2.0123 & 0.0065 & 0.20004 & 0.0009 \\
\hline & 0.021 & 0.99 & 0.1503 & 2.0137 & 0.0146 & 0.19997 & 0.0012 \\
\hline The effect of $\rho_{b}$ on growth rates & $\sigma_{\varepsilon_{b}}$ & $\rho_{b}$ & $\sigma_{b}$ & $E(g)$ & $\sigma_{g}$ & $E(L)$ & $\sigma_{L}$ \\
\hline \multirow[t]{8}{*}{ for benchmark variance } & 0.0402 & 0 & 0.0402 & 2.0127 & 0.0000 & 0.20026 & 0.0000 \\
\hline & 0.0400 & 0.1 & 0.0402 & 2.0135 & 0.0005 & 0.20025 & 0.0003 \\
\hline & 0.0384 & 0.3 & 0.0402 & 2.0148 & 0.0015 & 0.20023 & 0.0007 \\
\hline & 0.0349 & 0.5 & 0.0402 & 2.0152 & 0.0020 & 0.20018 & 0.0011 \\
\hline & 0.0287 & 0.7 & 0.0402 & 2.0153 & 0.0025 & 0.20012 & 0.0011 \\
\hline & 0.0266 & 0.75 & 0.0402 & 2.0130 & 0.0034 & 0.2001 & 0.0011 \\
\hline & 0.0175 & 0.9 & 0.0402 & 2.0075 & 0.0038 & 0.2000 & 0.0008 \\
\hline & 0.0057 & 0.99 & 0.0402 & 2.001 & 0.0039 & 0.2000 & 0.0003 \\
\hline The effect of $\eta$ on the relationship & & & & $E(g)$ & $\sigma_{g}$ & $E(L)$ & $\sigma_{L}$ \\
\hline \multirow[t]{3}{*}{ between volatility and growth } & \multicolumn{3}{|l|}{$\eta=1.2$} & 2.0110 & 0.0038 & 0.20006 & 0.0012 \\
\hline & \multicolumn{3}{|l|}{$\eta=3$} & 2.0081 & 0.0034 & 0.20006 & 0.0004 \\
\hline & \multicolumn{3}{|l|}{$\eta=5$} & 2.0075 & 0.0033 & 0.20006 & 0.0002 \\
\hline \multirow[t]{7}{*}{ Sensitivity } & & & & $E(g)$ & $\sigma_{g}$ & $E(L)$ & $\sigma_{L}$ \\
\hline & \multicolumn{3}{|c|}{$\beta=0.95$} & 2.0133 & 0.0036 & 0.20005 & 0.0008 \\
\hline & \multicolumn{3}{|c|}{$\beta=0.97$} & 2.0076 & 0.0037 & 0.20007 & 0.0010 \\
\hline & \multicolumn{3}{|c|}{$\delta=0.075$} & 2.0133 & 0.0038 & 0.20008 & 0.0013 \\
\hline & \multicolumn{3}{|c|}{$\delta=0.125$} & 2.0076 & 0.0036 & 0.2000 & 0.0007 \\
\hline & \multicolumn{3}{|c|}{$L=0.17$} & 2.0079 & 0.0033 & 0.1700 & 0.0007 \\
\hline & \multicolumn{3}{|c|}{$L=0.3$} & 2.0175 & 0.0049 & 0.3001 & 0.0018 \\
\hline
\end{tabular}


Table 6: Volatility of the Fiscal Shock under Competitive Labour Market

\begin{tabular}{|c|c|c|c|c|c|c|c|}
\hline Benchmark & $\begin{array}{c}\sigma_{\varepsilon_{u}} \\
0.010 \\
\end{array}$ & $\begin{array}{c}\rho_{u} \\
0.87 \\
\end{array}$ & $\begin{array}{c}\sigma_{u} \\
0.0206 \\
\end{array}$ & $\begin{array}{c}E(g) \\
2.0011\end{array}$ & $\begin{array}{c}\sigma_{g} \\
0.0008 \\
\end{array}$ & $\begin{array}{c}E(L) \\
0.2\end{array}$ & $\begin{array}{c}\sigma_{L} \\
0.0016 \\
\end{array}$ \\
\hline \multirow[t]{7}{*}{ The effect of $\sigma_{\varepsilon_{u}}$ on growth rates } & $\sigma_{\varepsilon_{u}}$ & $\rho_{u}$ & $\sigma_{u}$ & $E(g)$ & $\sigma_{g}$ & $E(L)$ & $\sigma_{L}$ \\
\hline & 0.005 & 0.87 & 0.0101 & 2.003 & 0.0004 & 0.2000 & 0.0008 \\
\hline & 0.03 & 0.87 & 0.0608 & 2.0091 & 0.0023 & 0.1999 & 0.0046 \\
\hline & 0.05 & 0.87 & 0.1014 & 2.0253 & 0.0038 & 0.1999 & 0.0077 \\
\hline & 0.07 & 0.87 & 0.1420 & 2.0495 & 0.0053 & 0.1998 & 0.0108 \\
\hline & 0.10 & 0.87 & 0.2028 & 2.1095 & 0.0084 & 0.1996 & 0.0155 \\
\hline & 0.125 & 0.87 & 0.2535 & 2.1711 & 0.0105 & 0.1993 & 0.0194 \\
\hline \multirow[t]{10}{*}{ The effect of $\rho_{u}$ on growth rates } & $\sigma_{\varepsilon_{u}}$ & $\rho_{u}$ & $\sigma_{u}$ & $E(g)$ & $\sigma_{g}$ & $E(L)$ & $\sigma_{L}$ \\
\hline & 0.010 & 0 & 0.0102 & 2.0003 & 0.0000 & 0.2000 & 0.0000 \\
\hline & 0.010 & 0.10 & 0.0102 & 2.0003 & 0.0000 & 0.2000 & 0.0000 \\
\hline & 0.010 & 0.30 & 0.0107 & 2.0004 & 0.0000 & 0.2000 & 0.0002 \\
\hline & 0.010 & 0.50 & 0.0117 & 2.0006 & 0.0002 & 0.2000 & 0.0003 \\
\hline & 0.010 & 0.70 & 0.0142 & 2.0008 & 0.0003 & 0.2000 & 0.0007 \\
\hline & 0.010 & 0.95 & 0.0326 & 2.0008 & 0.0015 & 0.2000 & 0.0030 \\
\hline & 0.010 & 0.97 & 0.0419 & 2.0002 & 0.0020 & 0.2000 & 0.0040 \\
\hline & 0.010 & 0.98 & 0.0025 & 1.9993 & 0.0511 & 0.2000 & 0.0051 \\
\hline & 0.010 & 0.99 & 0.0721 & 1.9967 & 0.0037 & 0.2000 & 0.0074 \\
\hline \multirow{8}{*}{$\begin{array}{l}\text { The effect of } \rho_{u} \text { on growth rates } \\
\text { for benchmark variance }\end{array}$} & $\sigma_{\varepsilon_{u}}$ & $\rho_{u}$ & $\sigma_{u}$ & $E(g)$ & $\sigma_{g}$ & $\overline{E E(L)}$ & $\sigma_{L}$ \\
\hline & 0.0206 & 0.10 & 0.0206 & 2.0012 & 0.0000 & 0.2000 & 0.0000 \\
\hline & 0.0197 & 0.30 & 0.0206 & 2.0015 & 0.0002 & 0.2000 & 0.0003 \\
\hline & 0.0179 & 0.50 & 0.0206 & 2.0017 & 0.0003 & 0.2000 & 0.0006 \\
\hline & 0.0165 & 0.60 & 0.0206 & 2.0017 & 0.0004 & 0.2000 & 0.0008 \\
\hline & 0.0147 & 0.70 & 0.0206 & 2.0017 & 0.0005 & 0.2000 & 0.0010 \\
\hline & 0.0090 & 0.90 & 0.0206 & 2.0008 & 0.0008 & 0.2000 & 0.0016 \\
\hline & 0.0029 & 0.99 & 0.0206 & 1.9997 & 0.0011 & 0.2000 & 0.0021 \\
\hline \multirow{4}{*}{$\begin{array}{l}\text { The effect of } \eta \text { on the relationship } \\
\text { between volatility and growth }\end{array}$} & & & & $\overline{E E(g)}$ & $\sigma_{g}$ & $\overline{E E(L)}$ & $\sigma_{L}$ \\
\hline & $\eta=1.2$ & & & 2.0007 & 0.0011 & 0.2000 & 0.0020 \\
\hline & $\eta=3$ & & & 2.0022 & 0.0004 & 0.2000 & 0.0007 \\
\hline & $\eta=5$ & & & 2.0027 & 0.0002 & 0.2000 & 0.0004 \\
\hline \multirow[t]{7}{*}{ Sensitivity } & & & & $E(g)$ & $\sigma_{g}$ & $E(L)$ & $\sigma_{L}$ \\
\hline & \multicolumn{3}{|c|}{$\beta=0.95$} & 2.0012 & 0.0001 & 0.2000 & 0.0017 \\
\hline & \multicolumn{3}{|c|}{$\beta=0.97$} & 2.0010 & 0.0008 & 0.2000 & 0.0015 \\
\hline & \multicolumn{3}{|c|}{$\delta=0.075$} & 2.0010 & 0.0007 & 0.2000 & 0.0015 \\
\hline & \multicolumn{3}{|c|}{$\delta=0.125$} & 2.0012 & 0.0010 & 0.2000 & 0.0017 \\
\hline & \multicolumn{3}{|c|}{$L=0.17$} & 2.0011 & 0.0008 & 0.1700 & 0.0013 \\
\hline & \multicolumn{3}{|c|}{$L=0.3$} & 2.0011 & 0.0008 & 0.3000 & 0.0024 \\
\hline
\end{tabular}


Figure 1: Volatility of the Monetary Shock under Monopolistic Nominal Wage Setting, $\rho_{a}=0.69$
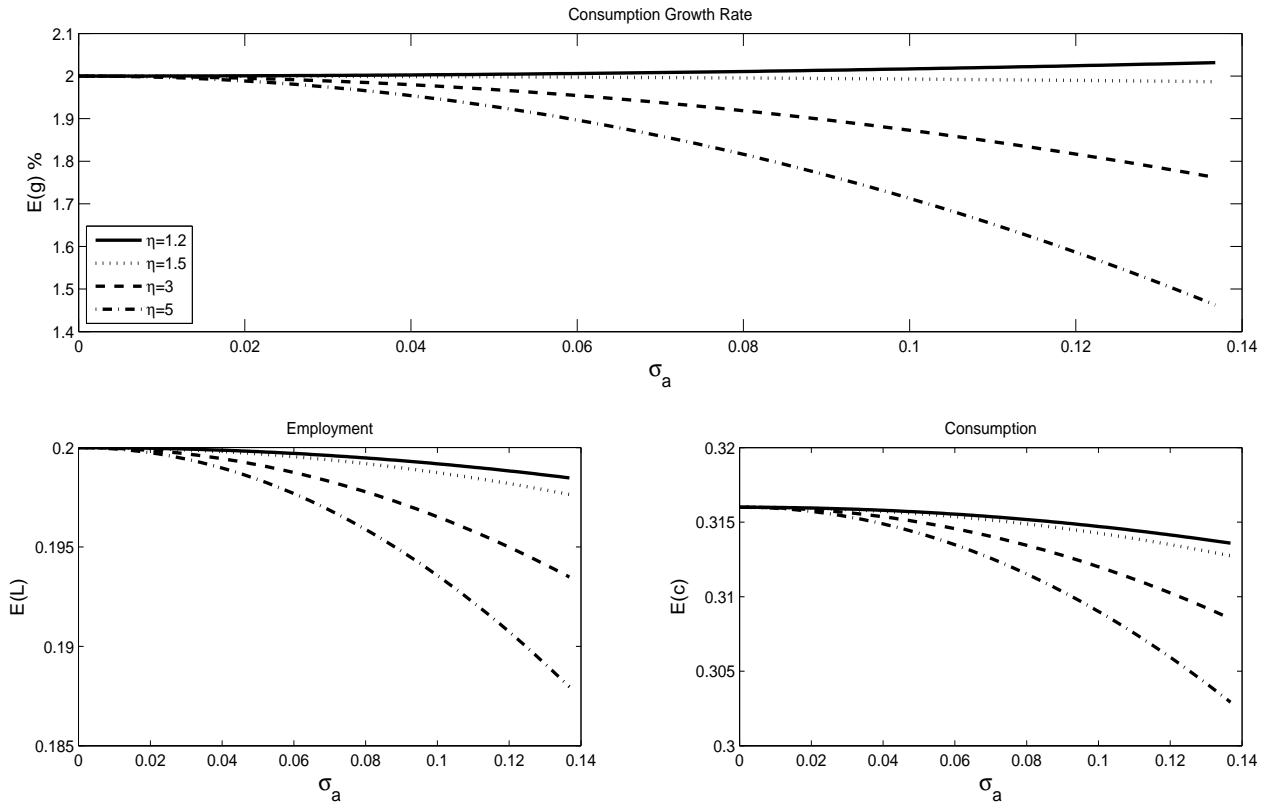

Figure 2: Volatility of the Technology Shock under Monopolistic Nominal Wage Setting, $\rho_{b}=0.85$
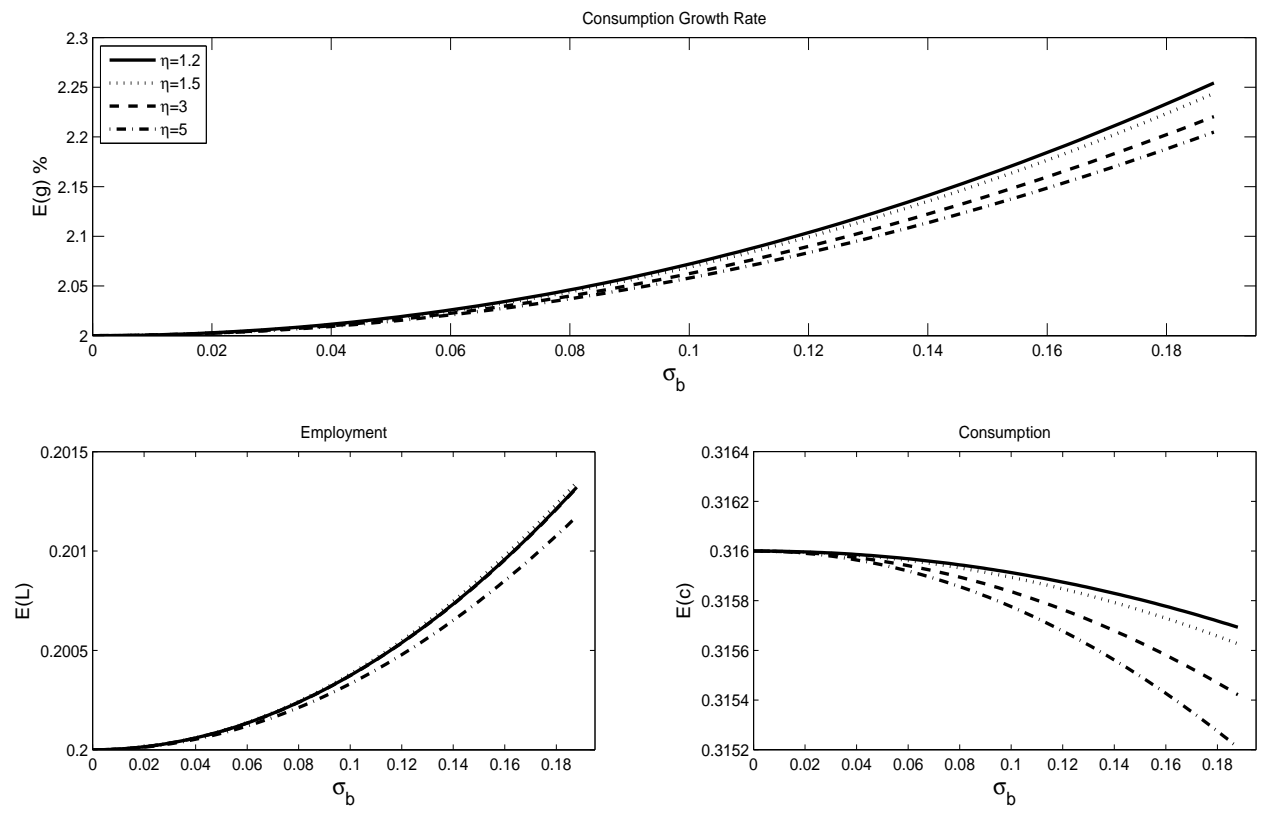
Figure 3: Volatility of the Fiscal Shock under Monopolistic Nominal Wage Setting, $\rho_{u}=0.87$
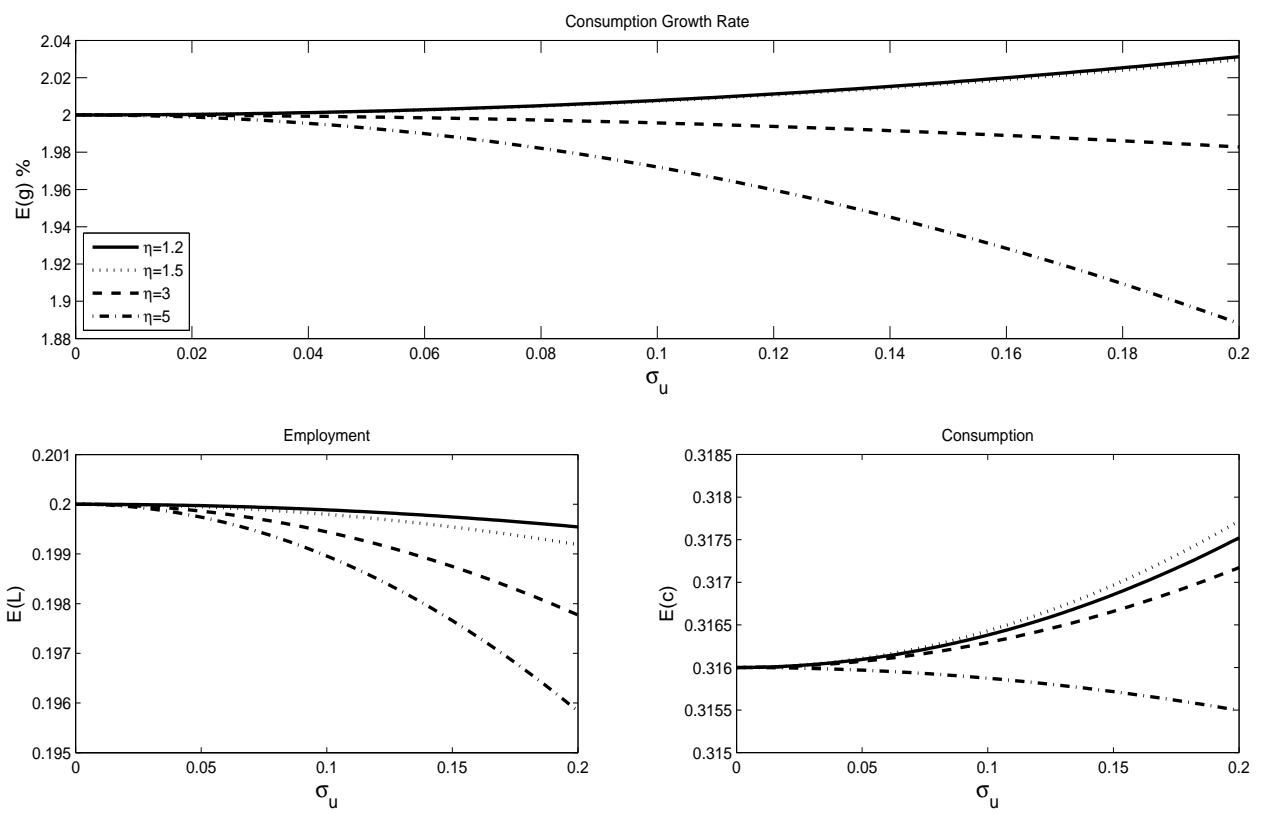

Figure 4: Persistence of the Technology Shock, $\sigma_{\varepsilon_{b}}=0.021, \eta=5$
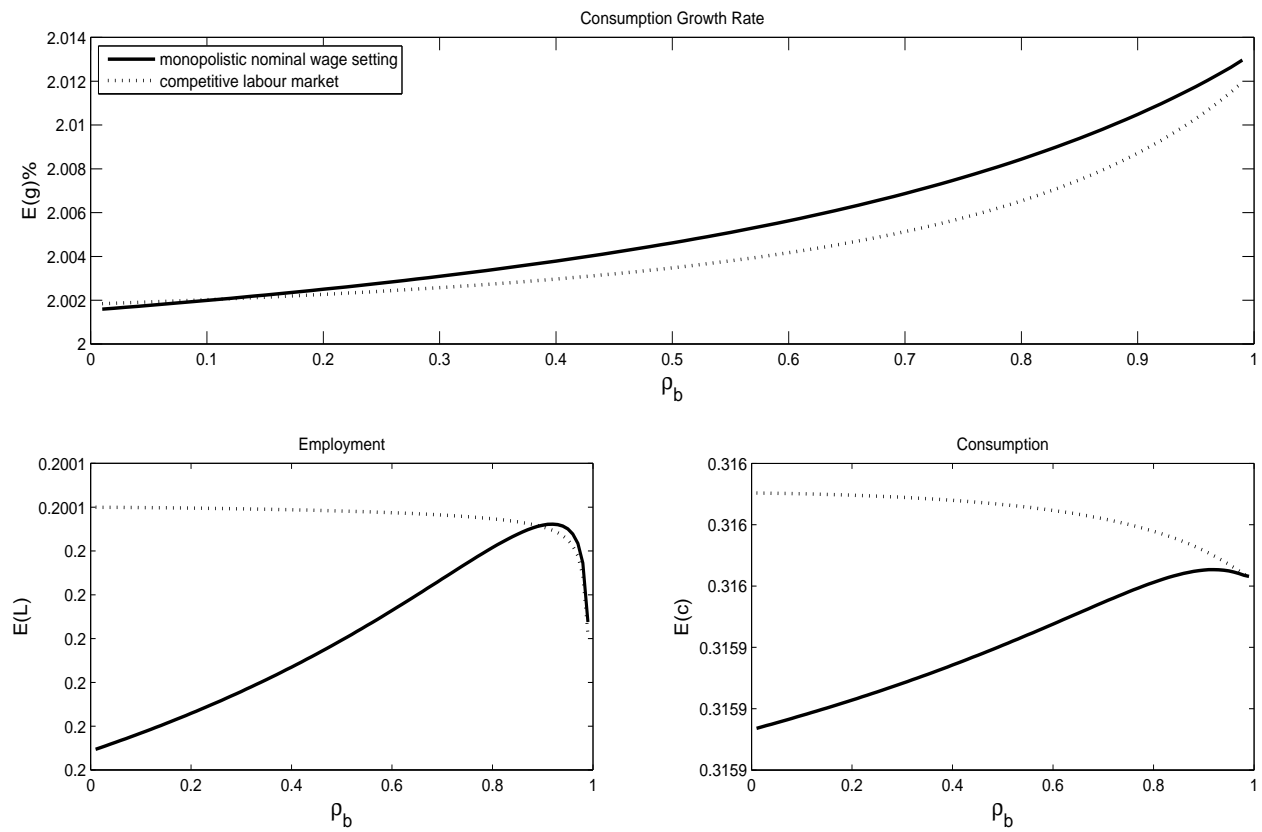
Figure 5: Persistence of the Fiscal Shock, $\sigma_{\varepsilon_{u}}=0.010, \eta=5$
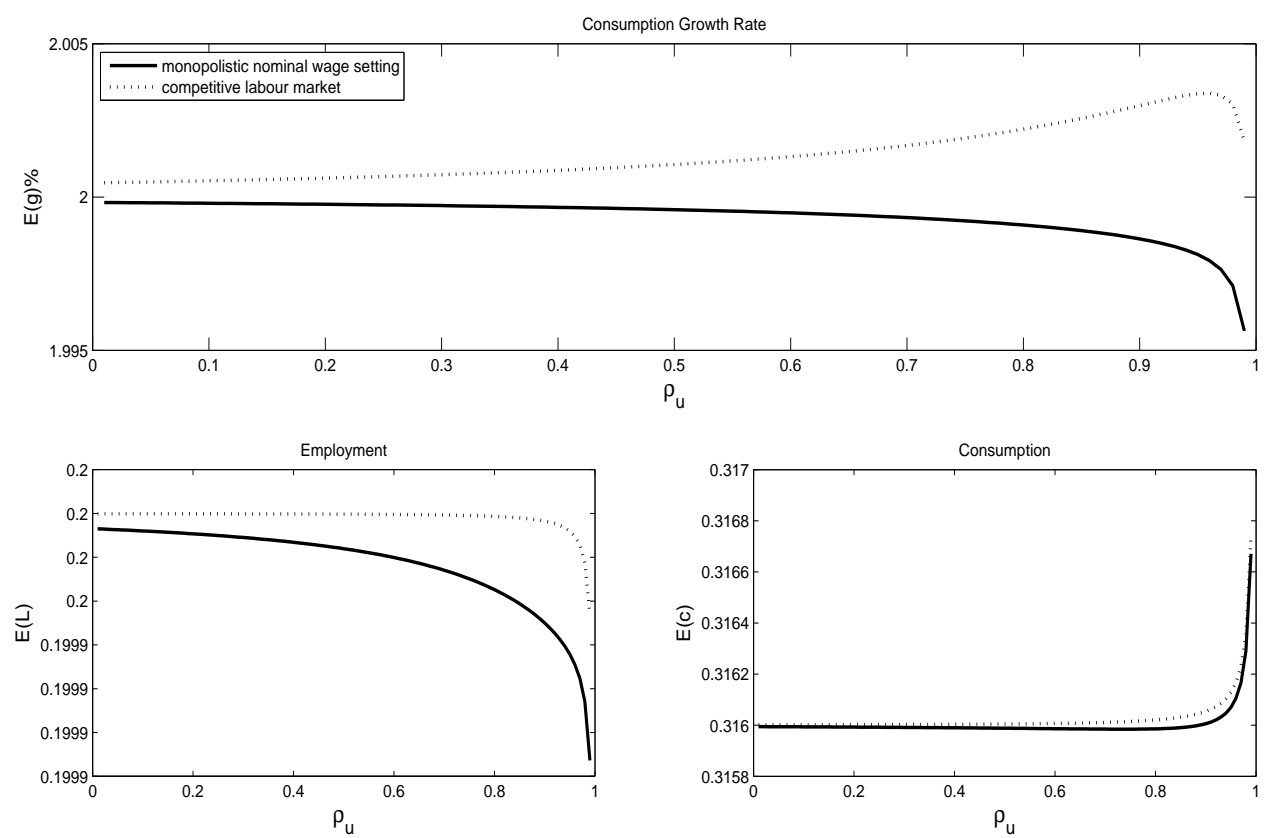